\title{
Militancias gráficas: carteles y solidaridad transnacional entre Francia y América Latina $1970-1980$
}

\section{Graphic Militancies: \\ Posters and Transnational Solidarity between France and Latin America 1970-1980}

\author{
Priscila Pilatowsky Goñi \\ (D) https://orcid.org/0000-0001-6610-2673 \\ IHEAL CREDA Paris 3 Sorbonne Nouvelle, Francia \\ ppilatowsky@gmail.com
}

\section{Amaia Cabranes \\ (1) https://orcid.org/0000-0002-4697-1289 \\ Universidad de Bordeaux Montaigne, Francia \\ amaiacabranes@gmail.com}

Resumen: La presente investigación explora las redes de solidaridad entre Francia y América Latina entre las décadas de 1970 y 1980, cuando esta última sufrió gobiernos dictatoriales. A partir del hallazgo de la colección de carteles de la Biblioteca Pierre Monbeig (IneAL, París), este artículo muestra las posibilidades del cartel como fuente para el estudio de estas redes. Desde la historia y los estudios visuales, el cartel revela la extensa constelación de entidades implica-

Cómo ciTAR: Pilatowsky Goñi, P. y Cabranes, A. (2020). Militancias gráficas: carteles y solidaridad transnacional entre Francia y América Latina 1970-1980. Secuencia (108), e1842. DoI: https://doi.org/10.18234/ secuencia.v0i108.1842 
das, desde las altas esferas oficiales, hasta los grupos "desde abajo". Probamos que París es un laboratorio para cuestionar lo local y lo global, donde la colaboración y la negociación se despliegan por encima de fronteras nacionales. Los carteles revelan las coyunturas, redes y prácticas de la solidaridad, y más allá, permiten indagar en la existencia de una "cultura visual" transnacional.

Palabras clave: cartel; Francia; América Latina; redes solidarias; estudios visuales.

Abstract: This research explores the solidarity networks between France and Latin America between the 1970s and 1980s, when the latter was governed by dictators. Based on the discovery of the collection of posters at the Pierre Monbeig Library (IHEAL, Paris), this article reveals their possibilities for studying these networks. Through history and visual studies, the poster reveals the vast constellation of entities involved, from the highest official spheres to grassroots groups. We show that Paris is a laboratory for interrogating the local and the global, where collaboration and negotiation take place across national borders. Posters reveal the conjunctures, networks, and practices of solidarity, and beyond that, they make it possible to explore the existence of a transnational "visual culture".

Key words: poster; France; Latin America; solidarity networks; visual studies.

Recibido: 6 de marzo de 2020 Aceptado: 3 de agosto de 2020

Publicado: 4 de diciembre de 2020

\section{INTRODUCCIÓN}

$\mathrm{U}^{\mathrm{n}}$ n cartel fechado el 2 de mayo de 1978, de autor anónimo, en azul, blanco y negro, muestra un dibujo con la escena de un partido de fútbol. Sobre la escena del partido se proyecta la sombra de otra escena en la que un hombre de atributos militares - lleva un casco y uniforme- apunta con una pistola a un hombre atado de manos y, aparentemente, arrodillado. El título del cartel convoca a "5 horas por el boicot del mundial" y el subtítulo anuncia el mo- 
tivo: "Contra la dictadura argentina. Solidaridad con el pueblo argentino". El cartel pide a los interesados en aquel deporte que se abstengan de apoyar la organización del evento. Además, revela que si bien Argentina iba a ser la sede de uno de los mayores eventos de entretenimiento y paz internacional, escondía una realidad de represión social que exigía ser denunciada (véase imagen 1$)^{1}$ (Contamin y Le Noé, 2010, pp. 27-46).

Este y otros carteles de protesta circularon en París durante las décadas de 1970 y 1980, cuando varios países latinoamericanos padecieron gobiernos dictatoriales. En Francia, la solidaridad con América Latina tuvo un gran dinamismo, en parte debido a la experiencia del movimiento de 1968, así como al recuerdo de la independencia de Argelia y a la emergencia de la nueva izquierda. Fue así que numerosos comités y asociaciones solidarias con América Latina, de diversa raigambre ideológica y espiritual, emprendieron acciones para informar, denunciar, ayudar, colectar fondos e integrar a los exiliados dentro del mundo laboral y cultural.

La noción de "solidaridad" puede rastrearse desde los escritos de Charles Fourier y Augusto Comte a principios del siglo xIX (Weiss, 2017). Sin embargo, la historiografía del tiempo presente inscribe las solidaridades transnacionales dentro del marco de la guerra fría, teniendo como casos emblemáticos los estudios sobre el comunismo internacional (Weiss, 2017). Nuevas orientaciones hacia América Latina han destacado la solidaridad en torno a la violencia por gobiernos represivos; los efectos del exilio, la lucha contra el imperialismo y el capitalismo, y la aparición de movimientos a favor de la paz y del medio ambiente. Estos estudios son un gesto del global/ transnational turn, que corre en paralelo con los estudios sobre la memoria, los derechos humanos, la historia de las organizaciones internacionales, y de la formación de una sociedad civil "global".

Al tratarse de un tema reciente no existe consenso metodológico. Desde la historia social y la historia política, algunos investigadores analizan las redes en torno a un acontecimiento muy resonado en Europa, como el golpe de Estado en Chile en 1973 (Christiaens, Goddeeris y Rodríguez, 2014; Compagnon, 2013) o la revolución sandinista (Agreda y Helm, 2016). Otros, estu-

${ }^{1}$ El cartel forma parte del fondo de la Biblioteca Pierre Monbeig (врм) del Institut des Hautes Études de l'Amérique Latine (IHEAL), París 3 Sorbonne Nouvelle, signatura AFF186. Está firmado por el Collectif pour le Boycott de l'Organisation par l'Argentine de la Coupe du Monde de Football (СОвA). 


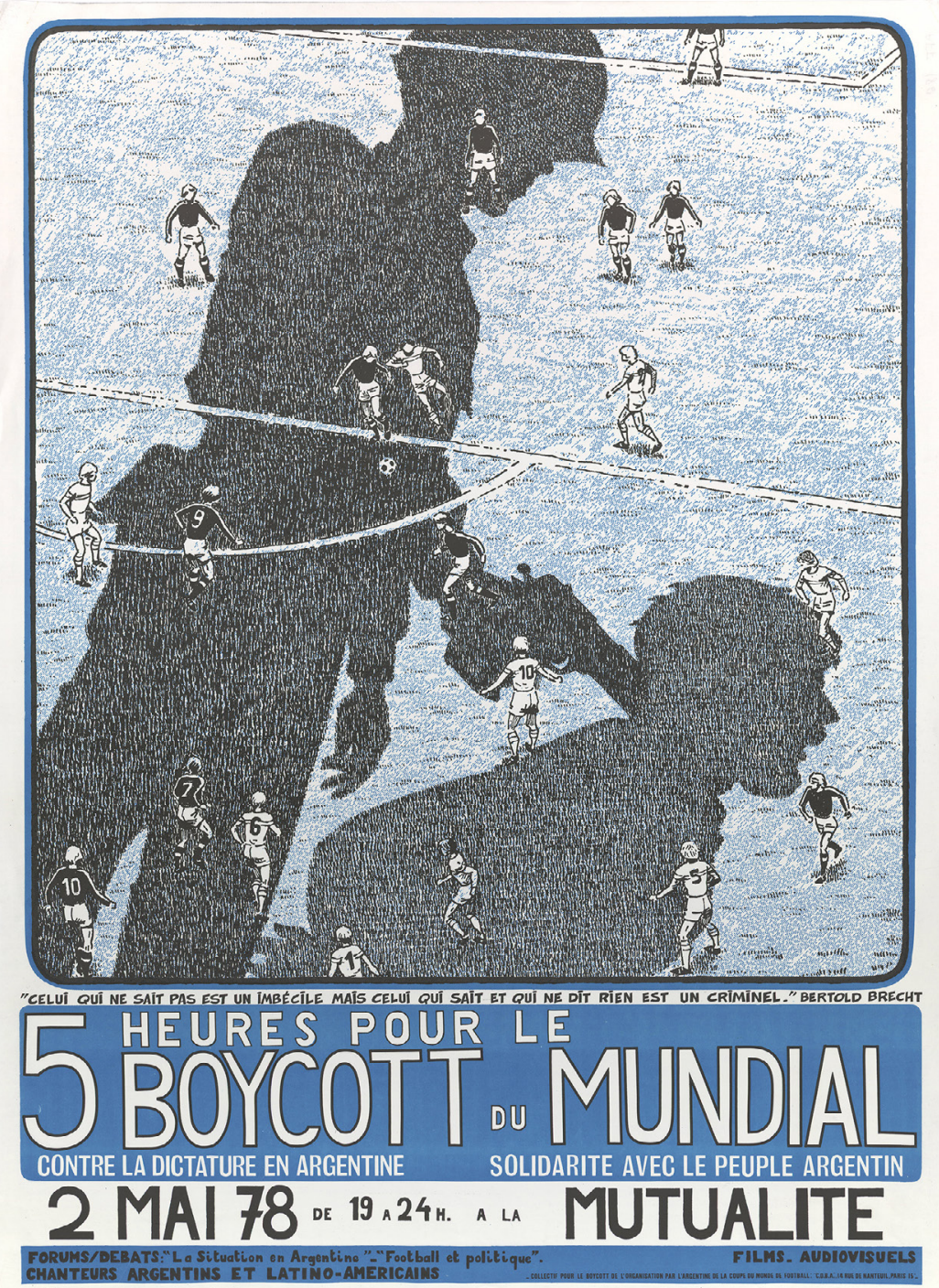

Imagen 1. Collectif pour le Boycott de l'Organisation par l'Argentine de la Coupe du Monde de Football (совA). En вPмIP, signatura AFF186. Todos los derechos reservados IHEAL, Paris 3, Sorbonne Nouvelle. 
dian fenómenos solidarios en marcos binacionales (De Giuseppe y Ágreda, 2016; Van Ommen, 2016). Cercanos a los estudios en medios de comunicación, otros académicos discuten el papel de las imágenes o de la prensa en la solidaridad (Blecha, 2016; Camacho Padilla y Ramírez Palacio, 2016). Desde enfoques cercanos a las relaciones internacionales y la historia intelectual, se exploran también la globalización de ideales universales, como los derechos humanos (Stites, 2014), o el imaginario de una sociedad "Tricontinental" (Garland, 2018).

En el caso específico de la solidaridad francesa, varios autores analizan la integración de exiliados latinoamericanos en la vida política, cultural y laboral del país galo. Franco y Tahir (2007), Plante (2013) y Franco (2004), examinan las acciones de exiliados argentinos en París. Prognon (2008) estudia las acciones militantes del exilio chileno, y en específico, la formación de una "cultura de la resistencia". Finalmente, el trabajo de Kalter (2016) es uno de los más completos por su mirada multidimensional de actores clave en la solidaridad francesa.

El presente artículo establece un diálogo entre la reciente historia de las solidaridades transnacionales con los estudios visuales (Mirzoeff, 1999) y la cultura visual (Mitchell, 1994). ${ }^{2}$ Su objetivo es mostrar la riqueza del cartel como fuente para indagar en las prácticas solidarias entre Francia y América Latina, así como reflexionar sobre el papel de este objeto en la comunicación militante y en la movilización gráfica. ${ }^{3}$

Nuestra investigación surgió con el hallazgo de los fondos de la Biblioteca Pierre Monbeig (BPM) del Institut des Hautes Études de l'Amérique La-

${ }^{2}$ Hacemos referencia al campo de estudios visuales (visual studies) que surgió en Estados Unidos a partir de la década de 1970. Su mayor exponente es W. J. T. Mitchell, quien propone analizar la "construcción social de la experiencia visual" a través del concepto de "giro pictorial" (pictorial turn), que supone un renovado interés por la relación entre texto e imagen. Los estudios visuales prefieren la cultura de masas y las artes populares que los temas tradicionales de la historia del arte. Por su parte, la cultura visual (Mirzoeff, 1999) analiza la presencia de los efectos de la imagen en la vida cotidiana en todos los medios en que se propagan, incluyendo la televisión, el cine, el internet, la publicidad, y cómo influyen los conceptos y las representaciones, por ejemplo, sobre el género, la identidad y raza.

${ }^{3}$ Nuestra reflexión se inspira en varias lecturas y exposiciones sobre el papel del cartel en las luchas políticas. Por ejemplo: Artivismo, 2016; Chambarlhac, Hage y Tillier, 2018; Graphisme alternatif et engagement politique après 1968 (Jornada de estudios EHESs, 12 de diciembre de 2014); Graphisme contemporain et engagement (Biblioteca Nacional de Francia, del 22 de septiembre al 22 de noviembre de 2015); López, Lebrero, Higueras y Reig, 2020; Fraenkel, Gouiran, Jakobowicz, Tesnière, 2013; Gastaut, 2019; Léger, 2013; Morales, 2008. 
tine (IHEAL), Paris 3 Sorbonne Nouvelle (en adelante BPMIP), que contiene 264 carteles producidos entre 1970 y 1998 fundamentalmente en Francia y en América Latina. De esta colección seleccionamos un corpus de 90 carteles creados en Francia y que expresan la militancia con los países latinoamericanos víctimas de dictaduras militares o de represión gubernamental. Los emisores de carteles, en su mayoría, se identifican con la izquierda (comités de apoyo, partidos políticos, sindicatos, instituciones culturales, asociaciones religiosas y otras entidades de apoyo a refugiados).

Este corpus constituye una fuente original, pues permite comprender el fenómeno solidario con datos ausentes en otros materiales y desde enfoques poco comunes para otras historiografías. De entrada, algunos carteles -sobre todo aquellos que llevan texto- permiten identificar la amplia constelación de entidades solidarias implicadas (comités, instituciones, asociaciones, iglesias) así como las múltiples interacciones (acciones, sedes, lugares de acción, imprentas, miembros en común). Algunas entidades eran muy conocidas en Francia, incluso en otros países. Sin embargo, otras gozaron de menor visibilidad, recursos y-suponemos- prestigio. En ambos casos, encontramos nombres de personajes distinguidos (artistas, intelectuales, diplomáticos, etc.) y también de personas cuya acción no dejó registro en fuentes más convencionales. En efecto, los carteles iluminan las redes de solidaridad dentro de París, tanto a nivel oficial, como en sus expresiones "desde abajo" (y estas últimas, muchas veces, condicionadas por la precariedad y la austeridad).

Los carteles revelan las variopintas maneras en que los exiliados latinoamericanos se integraron, se apropiaron y transformaron la vida cultural parisina y sus tradiciones militantes. La interacción con exiliados de otras regiones enriqueció la cultura y las estrategias de la protesta, además de alentar un genuino interés por las culturas "periféricas" en Francia. De hecho, los carteles dan testimonio de prácticas que difícilmente podemos calificar de "políticas" o "culturales". El entretenimiento, la música, la exhibición festiva, fueron recursos de igual valor para despertar la atención, reclamar y recaudar fondos. El cartel insiste en la transformación social -sin estar despojada de cierto tono moralizante-, en el valor de la filantropía, y en un vivo interés por la "cultura" de otros pueblos.

Los carteles nos tientan a reinterpretar lo global y lo local. Advertimos, por ejemplo, que las fronteras nacionales no suponen límites en los fenómenos solidarios y que las redes no se inscriben necesariamente en dinámicas binacionales. Los carteles proponen una heurística distinta para reconsiderar 
nuevas geografías. París funciona como un epicentro o laboratorio local donde un fenómeno global se expresa con gran dinamismo y vitalidad. Las redes solidarias en París fueron animadas por actores de diverso origen, filiación política, incluso credo religioso. Los carteles iluminan, precisamente, la convivencia, colaboración y negociación, pero también desencuentros y divergencias.

Por último, las iconografías remiten a una "cultura visual de la solidaridad" distribuida a nivel transnacional. Los colores, formas, tipografías y otros recursos visuales recurrentes indican genealogías, códigos, símbolos, y signos compartidos. Más allá, podemos preguntar si efectivamente existió una sensibilidad visual sin fronteras, por encima de las demandas políticas y el discurso escrito. En suma, si la historia de las solidaridades ha preferido registros textuales -boletines, memorias- o sonoros (en el caso de fuentes orales), es pertinente indagar en el papel de lo gráfico en la formación de simpatías comunes a lo largo del mundo.

\section{LOS AÑOS 1960-1980: ENTRE DICTADURAS Y UNA "NUEVA IZQUIERDA"}

Entre las décadas de 1960 y 1980, varios países latinoamericanos padecieron turbulencias políticas que a menudo desembocaron en gobiernos represivos, guerras civiles, crisis económicas, conflictos sociales e intervenciones de Estados Unidos. En 1964, un golpe militar en Brasil depuso al presidente Joao Goulãrt e instaló una dictadura. En 1966 comenzó la "revolución argentina" -como se conocen los gobiernos represivos de Juan Carlos Onganía, Roberto Levingston y Alejandro Lanusse- provocando un exilio masivo. Al golpe a Salvador Allende, en septiembre de 1973, siguió la dictadura de Augusto Pinochet. Un año después muere Juan Perón en Argentina dejando en el poder a su viuda Isabel, depuesta en 1976 por militares al mando de Jorge Rafael Videla. También en 1974, Nicaragua conoció una intensa guerra civil entre el gobierno de Somoza y el Frente Sandinista de Liberación Nacional (FSLN). El triunfo sandinista y sus supuestas filiaciones con la Unión Soviética dieron pretexto a la intervención estadunidense mediante el apoyo al ejército contrarrevolucionario mejor conocido como los “contras". Guatemala, por su parte, sufrió una guerra civil que duró 36 años (1960-1996).

Este contexto de violencia favoreció el surgimiento de una nueva izquierda latinoamericana. Varios autores coinciden en que ninguna definición 
precisa a describir la complejidad de sus integrantes, que evidentemente emergieron en contextos sociopolíticos y geográficos muy distintos (Picker, 2017; Tortti, 2014). No obstante sus diferencias, tenían un "ethos común" que consistía en establecer una forma de utopía revolucionaria internacional. Según Martín y Rey (2017), estos grupos compartían repertorios de acción, marcos de interpretación de la realidad y formas de organización comunes (p. 19). Además, todos tenían como referencia a la revolución cubana (1959), que promovió la idea de la necesidad de la violencia para alcanzar la liberación ante los gobiernos represivos. De Cuba irradiaron modelos de acción y un marco ideológico en que destacan las nociones de "antiimperialismo, liberación nacional, revolución y conflicto armado" (p. 6). Entre las referencias intelectuales de las izquierdas estaban los escritos de Che Guevara, Herbert Marcuse, Frantz Fanon, Louis Althusser, sin dejar de mencionar la influencia de la "teoría de la dependencia" y la teología de la liberación (tras la formación del Consejo Episcopal Latinoamericano [CELAM]).

Del otro lado del Atlántico, varios países europeos buscaban nuevas alternativas políticas y formas de consenso social, especialmente después de los sucesos de mayo de 1968, que legaron una gran sensibilidad hacia la represión de Estado (Kalter, 2016, pp. 1-2). En Francia estaba latente el recuerdo de la independencia de Argelia (1954-1962) que, junto a otros procesos de descolonización, hicieron de París un punto de encuentro panafricanista. Por otra parte, varias organizaciones no gubernamentales, francesas e internacionales, creadas al terminar la segunda guerra mundial, se movilizaron para asistir a los refugiados políticos latinoamericanos. Entre las mejor conocidas estaban Secours Populaire, France Terre d'Asile, Amnistía Internacional, y el Comité Inter-mouvements Auprés des Évacués (CIMADE). Fue crucial, además, la presión que ejercieron intelectuales y artistas franceses ante el gobierno francés para que apoyara a exiliados y refugiados de muchos espacios del mundo.

En Europa también se formó una nueva izquierda como producto de una crisis de narrativas que habían estructurado las relaciones internacionales del siglo xx: el comunismo soviético, el catolicismo, el capitalismo y el fascismo. Según Judt (2005) esta noción surgió en 1965, como una respuesta a la violencia en el "tercer mundo" y se distinguió respecto a una vieja izquierda en que dejó de reconocer al proletariado como la clase oprimida dominante y único vehículo posible de la transformación social. Su inspiración comenzó a hallarse en los conflictos del "tercer mundo", luego de las independencias africanas, la lucha contra la exclusión de los afrodescendientes en Estados 
Unidos, los movimientos indigenistas, las demandas cívicas contra la violencia, y las guerrillas latinoamericanas. La nueva izquierda (tanto en Francia como en otros países, incluyendo América Latina) amplió su agenda más allá de lo político y abogó por el medio ambiente, los derechos humanos (niños, mujeres, indígenas), la lucha contra el hambre, el anticapitalismo, y el antiimperialismo (pp. 404-407).

\section{LA COLECCIÓN DE CARTELES DE LA BIBLIOTECA PIERRE MONBEIG}

La Biblioteca Pierre Monbeig alberga un fondo de 264 carteles producidos entre 1970 y 1998 en Francia y en América Latina. Este fondo se ha ido conformando de manera paulatina y espontánea gracias a las donaciones voluntarias de individuos, museos, instituciones, y sociedades políticas y ciudadanas. ${ }^{4}$ Entre los donadores figuran: la OSPAAAL ${ }^{5}$ y la OCLAE $^{6}$ cubanas -lo que no extraña, dadas las buenas relaciones entre la embajada de Cuba y el IHEAL-; la comunidad académica de esta institución (incluyendo profesores, estudiantes, personal administrativo, exiliados latinoamericanos y personalidades del medio intelectual); así como imprentas independientes. ${ }^{7}$ El fondo se digitalizó con el concurso de la Biblioteca Nacional de Francia y por iniciativa del entonces director del IHEAL, Olivier Compagnon (2015-2019).

Esta colección es muy relevante en Francia, no sólo por el prestigio de la institución que la acoge -el IHEAL es el centro de estudios latinoamericanos más importante del país, frecuentado por una comunidad académica inter-

${ }^{4}$ Gracias a la colaboración de los directores de la biblioteca, Bruno Bonnenfant y François Merveille, conocemos los datos de la colección que se exponen en este texto. Ellos nos brindaron, además, acceso a los carteles digitalizados y a los registros en Excel.

${ }^{5}$ La Organización de Solidaridad con los Pueblos de Asia, África y América Latina (osPAAAL) surgió durante la conferencia Tricontinental (1966), que reunió a representantes de los países llamados "no alineados" y de movimientos anticoloniales, con el objetivo de alcanzar la paz y proclamar el socialismo. Esta fue una de las grandes propagandistas de la creatividad y técnica del cartel cubano. Véase la revista Tricontinental, que puede consultarse en la biblioteca La Contemporaine, París Nanterre.

${ }^{6}$ La Organización Continental Latinoamericana y Caribeña de Estudiantes (OCLAE) se fundó en La Habana, Cuba, en 1966.

${ }^{7}$ Es posible que otros carteles hayan sido remanentes de imprentas que se enviaron al IHEAL para exponerlos en sus muros, pues la colección dispone de varios ejemplares de un mismo cartel. 
nacional-. Muchos de sus ejemplares no fueron preservados por otras bibliotecas, archivos o colecciones privadas. Son vestigios únicos, improbables, que junto con otras fuentes nos hablan del medio político, cultural e intelectual de la historia reciente.

El registro del fondo (en Excel), clasifica los carteles por: título, país, autor, año, dimensiones y signatura. Sin embargo, descarta informaciones que se escriben en el cartel como: autor (en caso de haberlo), nombres de grupos implicados, direcciones, fechas, nombre de la imprenta (escrito en caracteres muy pequeños) y elementos iconográficos (imagen, estilo, colores, etc.). Más allá del registro, los ejemplares físicos del fondo ofrecen datos sobre su contexto. Por ejemplo, no todos eran carteles (algunos eran hojas recortadas de alguna revista, otros tenían hojas pegadas, alterando la imagen original); los tamaños y la calidad de papel es diversa (lo que revela una probable superioridad técnica y económica de ciertos grupos); huellas de chinchetas (indicio de que alguna vez fueron expuestos), e inscripciones manuscritas al dorso o en otro espacio de la imagen. La mayoría privilegian la disposición vertical aunque hay ejemplares horizontales. Cuatro carteles son manuscritos sobre cartulina, el resto son impresos (serigrafías y offset) sobre papel de diferentes calidades. La mayoría incluye dibujos, aunque 20 ejemplares integran fotografías.

Del conjunto de 264, seleccionamos un corpus de 90 carteles que refieren a una solidaridad militante entre Francia y América Latina. Estos fueron producidos por comités de apoyo a exiliados y prisioneros políticos, instituciones francesas, organizaciones no gubernamentales y partidos políticos latinoamericanos en el exilio. Discriminamos los carteles de la OSPAAAL porque no tratan directamente la relación Francia-América Latina. ${ }^{8}$

En su mayoría, los carteles carecen de rúbrica u otro identificador de su autor. Entre los pocos nombres que logramos reconocer están los de Siné, Pedro Uhart, José Balmes, René Portocarrero, María Amaral, y otros, de quienes no hemos obtenido datos biográficos, como Jenny, JP Ader, J. Borges, FBI, Claire Lucas, Dominique Léfebvre, Christian Poveda, Boixader, Lacroix, Condor, Michael Ryba, Claudio Morra, LPLo, Guilleromo (nombre casi ilegible). $\mathrm{El}$ anonimato en los carteles de protesta los distingue respecto a los carteles de

\footnotetext{
${ }^{8}$ Los carteles de la OSPAAAL en el corpus (doce carteles) refieren la solidaridad entre Cuba con Angola, Palestina, Haití, Guinea, Kampuchea, Camboya, Corea, Sudáfrica. Por su parte, los de la oclae (24 carteles) también revelan la solidaridad del país caribeño con Chile, Nicaragua, Panamá, Paraguay, Puerto Rico, El Salvador y Brasil.
} 
autor que circularon, por ejemplo, durante las guerras mundiales y las campañas de publicidad turística. De hecho, parece que esta ausencia era una estrategia de la clandestinidad y una forma de rebelión. Según Gervereau (1988), "La primacía del anonimato es una característica del cartel militante en un medio que reclama el fin del individualismo y la primacía de lo colectivo" (p. 182).

Tras estas consideraciones, elaboramos una nueva base de datos en File Maker y en Excel donde incluimos la información del registro original junto con datos a partir de nuestras observaciones. ${ }^{9} \mathrm{El}$ producto de esta base se muestra en la gráfica 1 , que identifica el número de carteles por país con el que Francia establece acciones solidarias.

\section{LA SOLIDARIDAD EN EL ESPACIO}

Las direcciones disponibles en los carteles, recogidas en la base de datos, permiten visualizarlas geográficamente con Google Maps. Este mapeo indica la ubicación de sedes, lugares de reunión e imprentas, lo cual constituye una vía para indagar sobre las relaciones de cercanía entre comités e instituciones, así como en su posible interacción con las actividades de los distritos (arrondissements) de la ciudad.

En el mapa 1 advertimos que las sedes estaban distribuidas casi equitativamente a ambos lados del río Sena, en un eje sur-norte. ${ }^{10}$ No se concentraban en un distrito o en un conjunto de barrios, sino en ciertos núcleos emblemáticos de la vida cultural parisina, y muchos de ellos, de tradición contestataria. Por ejemplo, la sede de la Association des Familles des Disparus (número 18 de la calle Varenne), estaba muy cerca del boulevard Raspail y de la calle de Saint Guillaume, donde están los edificios del IHEAL, Sciences Po, la Escuela de Altos Estudios en Ciencias Sociales (eHEss) y la Maison de

${ }^{9}$ La base de datos incluye: título de la imagen, tema, función (información, propaganda, publicidad), emisor, dirección, países implicados, año de producción del cartel (en caso de haberlo), elementos iconográficos, lugar y fecha de la acción que anuncian, imprenta, y un apartado abierto para la descripción (dimensiones, materialidad, iconografía, referencias a artículos, libros, páginas web, etc.).

${ }^{10}$ Este mapa contiene únicamente las direcciones que aparecen en los carteles. De ningún modo constituye un registro exhaustivo de la ubicación de las sedes de comités. Esta información está siendo recabada para próximas etapas de esta investigación. 


\section{Gráfica 1. Solidaridad francesa con países latinoamericanos. Número de carteles por país}

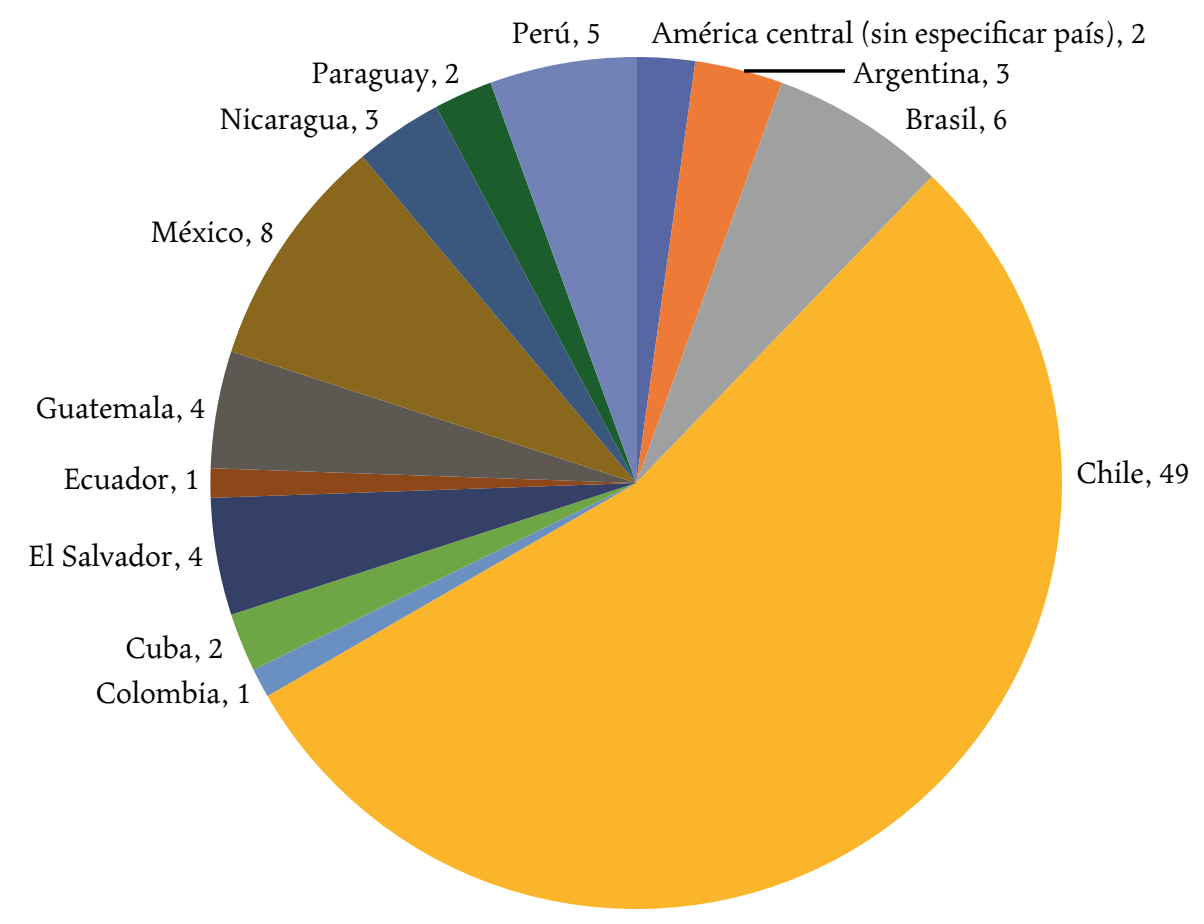

Fuente: elaborado a partir de los registros de carteles de la Biblioteca Pierre Monbeig. 
Mapa 1. Sedes de comités y asociaciones solidarias

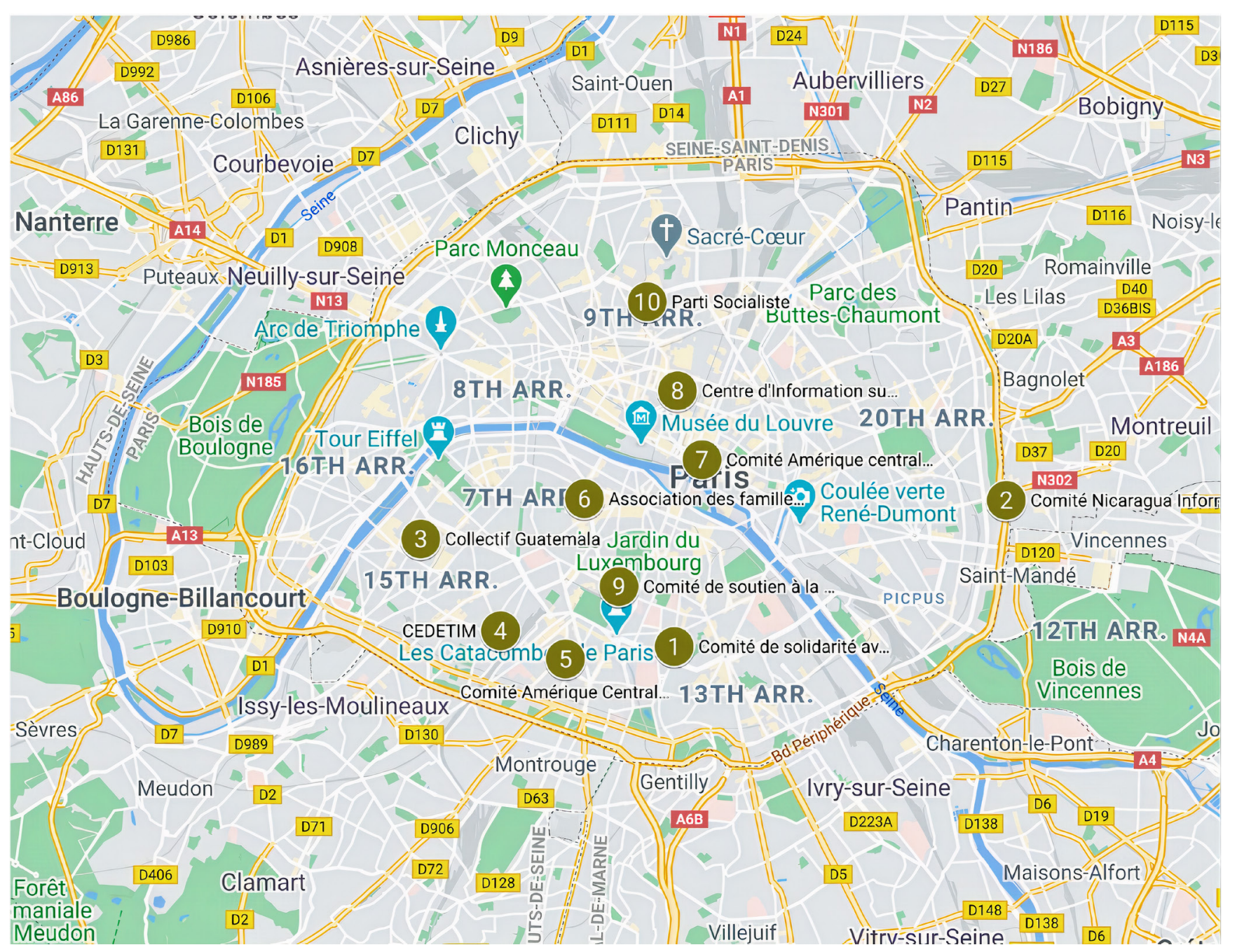

Fuente: Mapa elaborado por las autoras con base en Google Maps, a partir de las direcciones que aparecen en algunos carteles de la BPMIP.
1. Comité de Solidarité Avec la Lutte du Peuple de El Salvador. 45, bis rue de la Glacière, Paris, 75013.

2. Comité Nicaragua Information. Avenue Benoît Frachon, 75020 Paris, France.

3. Collectif Guatemala. 67 Rue du Théâtre, 75015 Paris, France.

4. Centre d'Études et d'Initiatives de Solidarité Internationale (CEDETIM). 14, rue Nanteuil.

5. Comité Amérique Centrale du 14e. 35, rue Olivier Noyer, 75014 Paris.

6. Association des Familles des Disparus. 18, rue de Varenne, 75007 Paris.

7. Comité Amérique Central Oscar Romero/Église Saint Merri. 78 Rue Saint-Martin, 75004 Paris, France.

8. Centre d'Information Sur la Lutte Anti-impérialiste cILA. 17 Rue du Sentier, 75002 Paris, France.

9. Comité de Soutien à la Lutte Révolutionnaire du Peuple Chilien. 94 Rue Notre Dame des Champs, 75006 Paris, France.

10.Parti Socialiste. 12 Cité Malesherbes, 75009 Paris, France. 
l'Amérique Latine, que se implicaron en numerosos eventos de solidaridad, académicos y culturales. ${ }^{11}$

La iglesia de Saint-Merry, en el barrio Le Marais, parecía compartir espacio con el Comité Amérique Centrale Oscar Romero (núm. 7). Este barrio del corazón de París, de origen judío y actualmente gentrificado, es uno de los más antiguos de la ciudad. La iglesia Saint Merry, situada entre el Museo Georges Pompidou y la torre Saint-Jacques, albergó varios eventos solidarios afines a la teología de la liberación, como se advierte en un cartel que muestra la imagen de un Cristo en colores y convoca al evento "Solidarité des églises d'America Latina" (véase imagen 2). Saint Merry también organizó numerosas actividades conjuntas con el Comité Catholique contre la Faim et le Développement (CCFD), que sigue activo hasta la fecha.

Ciertos comités se ubicaban en barrios de numerosa población migrante y obrera. Por ejemplo, el Comité Nicaragua Information estaba muy cerca de la Puerta de Montreuil, vecino al edificio que actualmente alberga las oficinas de la Confederación General del Trabajo (CGT) (núm. 2). En esta zona, y en particular el área que colinda con el distrito xI de París, se situaban algunas imprentas independientes que editaron algunos carteles de nuestro corpus, como Darboy (Montreuil, sin dirección), Primavera (70, rue des Maraîchers), NPP (56, rue des Haies) y Rotographie (2, rue Richard Lenoir, Montreuil). Cabe mencionar que la Puerta de Montreil y la plaza de Nation han sido, hasta la fecha, importantes centros de congregación de multitudes.

Otros comités, como el Centre d'Etudes et d'Initiatives de Solidarité Internationale (CEDETIM), y una de las sedes del Comité Amérique Centrale (Oscar Romero), estaban cerca de la ciudad Universitaria, que reúne las casas de varios países, como la Maison de Brésil, que organizó conciertos solidarios. El edificio del cedetim en la rue Nanteuil (núm. 4), según Kalter (2016), era una "colmena de activistas" (p. 416). ${ }^{12}$ Este Centro era uno de los principales asociados con el Comité de Soutien à la Lutte Révolutionnaire du Peuple Chilien, aunque su sede se ubicaba en Montparnasse (94, rue Notre-Damedes-Champs). El edificio del CEDETIM albergaba al Centre International de Culture Populaire (CICP) y varios comités y asociaciones, como el Comité de

${ }^{11}$ Varios carteles de nuestro corpus permiten constatar estas actividades.

${ }^{12}$ Véase la página oficial del CICP en http://www.cicp21ter.org/. Actualmente se encuentra en 21, Rue Voltaire. El cicP está activo hasta nuestros días y sigue apoyando la lucha a favor de los derechos humanos, la solidaridad con los migrantes, y apoya a las asociaciones de solidaridad internacional. 


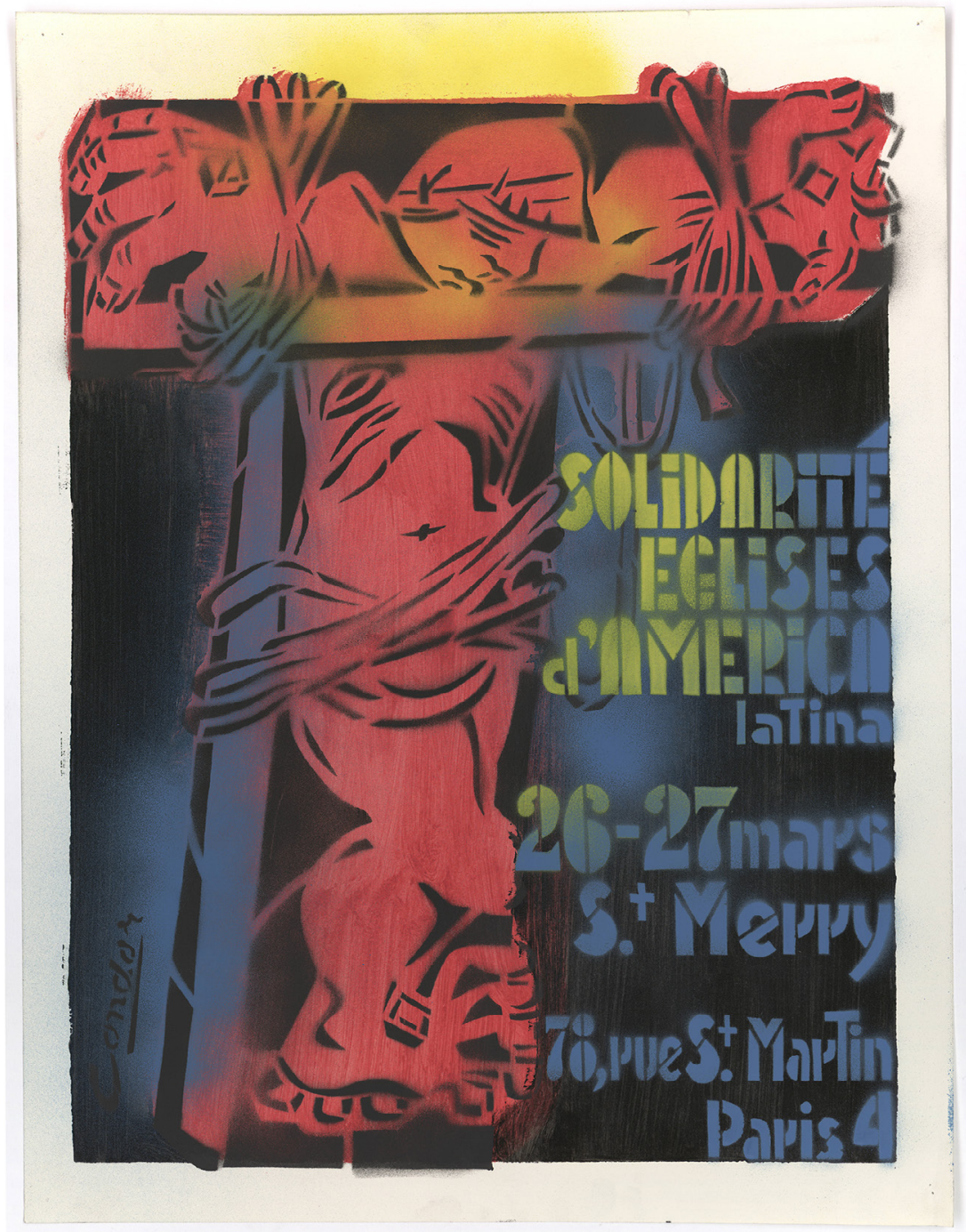

Imagen 2. Solidarité des Églises d'América Latina. En вPMIP, signatura AFF037. Todos los derechos reservados ineal Paris 3, Sorbonne Nouvelle. 
Solidarité Avec le Peuple Mexicain, y el Collectif pour le Boycott de l'Organisation par l'Argentine de la Coupe du Monde de Football (совA).

\section{HACIA UNA PERIODIZACIÓN DE LA SOLIDARIDAD EN FRANCIA}

La mayoría de los carteles del corpus refieren la solidaridad de Francia con Chile (49). De ellos, doce se relacionan con el Comité de Soutien à la Lutte Révolutionnaire du Peuple Chilien; tres con el Movimiento de Izquierda Revolucionaria (MIR), seis con el Partido Socialista Chileno; y el resto, con otros colectivos de apoyo. El resto del corpus expresa solidaridad con otros países latinoamericanos en el marco de diversas coyunturas, entre otras: la lucha por los derechos humanos y el antiimperialismo en El Salvador, Guatemala y Nicaragua, o el llamado al boicot a la Copa Mundial de Fútbol de 1978 en Argentina.

La falta de información sobre las fechas de producción y distribución de los carteles supone un reto. No obstante, el diseño gráfico, la calidad física, las elecciones cromáticas y el tema, son indicios para una probable datación. De acuerdo con las fechas registradas y las sugeridas por la investigación, todos los carteles producidos entre 1973 y 1976 conciernen la solidaridad con Chile, mientras que todos los registrados entre 1981 y 1983 se refieren, en su totalidad, a Centroamérica.

Si bien es cierto que la solidaridad entre Francia y América Latina no comienza con el golpe de Estado en Chile,$^{13}$ este evento la propulsó de manera exponencial. Compagnon (2013) afirma que el golpe fue un "choque emocional planetario que debe ser pensado como uno de los momentos más importantes de las sensibilidades políticas contemporáneas" (p. 99). Según Volovitch-Tavares (2013), "la sensibilidad de la opinión francesa a los eventos de Chile fue más fuerte respecto a otras dictaduras latinoamericanas y sobrepasó los medios habituales de la izquierda, la extrema izquierda y las asociaciones humanitarias". Evidentemente, la solidaridad fue fruto de la extrema represión. Pero según ella, además, las formaciones políticas de la izquierda chilena que integraron la Unidad Popular (socialistas, comunistas, la izquierda cristiana), "eran afines a ciertas agrupaciones de la izquierda francesa, en

${ }^{13}$ El golpe de Estado a Arturo Ilia, en Argentina, y la dictadura que derrocó a Joao Goulart, en Brasil, provocaron salidas masivas de exiliados en la década de 1960. 
relación con los grupos políticos perseguidos por las dictaduras de otros países latinoamericanos como Brasil o Argentina" (p. 51).

En este sentido, es pertinente proponer que la historia de la solidaridad en Francia experimenta una reorganización importante a partir de 1973; el foco de la atención francesa se desplaza a la región centroamericana desde 1979, y hacia la década de 1980, la solidaridad se extiende a los derechos humanos, a la lucha a favor del medio ambiente, por la paz, y contra la desigualdad.

En su estado actual, esta investigación no ha concluido un estudio exhaustivo de otros fondos de carteles en París. Sin embargo, los registros de esos fondos e investigaciones recientes sobre ellos permiten validar esta periodización. La biblioteca La Contemporaine alberga una nutrida colección de materiales sobre el golpe de Estado en Chile ${ }^{14}$ que ha sido objeto de seminarios e investigaciones. ${ }^{15}$ Los autores del catálogo de la exposición Internationales Graphiques (Tardy y Tesnière, 2016) ${ }^{16}$ consideran clave el periodo de 1970 a 1990 y reconocen al golpe de Estado chileno como su mayor acicate en América Latina. Uno de ellos es Julien Hage (2016, pp. 47-51), quien apunta que tras este evento se formaron en Francia 18 organizaciones sindicales y partidos de izquierda que denuncian el terror y la represión, que a su vez generaron 400 comités de solidaridad. La magnitud de la solidaridad con Chile también es tangible en otras colecciones del mundo. ${ }^{17}$

${ }^{14}$ Entre ellos están la abundante folletería del Comité de Soutien à la Lutte Révolutionnaire du Peuple Chilien (CSLRPC) y de otros grupos políticos en el exilio. Por ejemplo: Chili. L'affrontement de Clases; Chili, la Gauche Chrétienne Lutte; Chili, ta Souffrance d'aujour'hui Prepare la Victoire de Demain; Chili, une Arme Au-dessus des Clases?; Sauvons les Prisonniers Politiques Disparus au Chili; además de los boletines del CeDETim.

${ }^{15}$ Cabe mencionar el seminario "Sources et archives audiovisuelles de la solidarité internationale, le cas chilien", dirigido por Caroline Moine (2015), llevado a cabo entre octubre de 2015 y junio de 2016, sin hablar de la abundante producción científica en Francia sobre este evento.

${ }^{16}$ La exposición Internationales Graphiques se llevó cabo en la biblioteca La Contemporaine del 7 de febrero al 29 de mayo de 2016.

${ }^{17}$ Por ejemplo, los fondos del International Institute of Social History (Amsterdam), el Museo de la Memoria y los Derechos Humanos (Santiago de Chile) y el Museo Internacional de la Resistencia Salvador Allende en París (Lebeau, 2018). 


\section{LOS COMITÉS Y SUS RELACIONES}

De los pocos carteles que registran la entidad que los produjo identificamos 46 distintas, que incluyen comités, colectivos, sindicatos, partidos políticos, centros de información, casas culturales y museos (véase cuadro 1). Asimismo, observamos que los comités de solidaridad podían tener delegaciones repartidas en varios barrios de París, en los alrededores de la ciudad (banlieue), o en otros departamentos de Francia. Suponemos que algunos comités eran suficientemente importantes para sumar varias sedes. El Comité de Soutien à la Lutte Révolutionnaire du Peuple Chilien tenía una filial en Ermont-Eaubonne-Taverny. ${ }^{18} \mathrm{El}$ Comité Amérique Central tenía al menos distintas representaciones en los distritos 14, 18 y 19 de la ciudad y otra delegación denominada Comité Amérique Central Oscar Romero. ${ }^{19}$

En los carteles se advierte que los comités estaban interconectados y eran relativamente porosos. Podían actuar coordinadamente en eventos o acciones, compartían sedes o sitios de reunión y, probablemente, algunos miembros formaban parte de más de un comité. Esta colaboración conjunta se revela en un cartel emitido por la Coordination des Comités Latino-américains, contra la intervención estadunidense en América Central. La Coordination reunía representantes de El Salvador, Honduras, Nicaragua, Cuba, Granada, Guatemala y Panamá..$^{20}$ Dos carteles que denuncian la represión en Guatemala y Argentina fueron comprados en un mitin de solidaridad con El Salvador en París Mutualité en marzo de 1981, como lo indica una nota manuscrita en el reverso de ambos. ${ }^{21}$ Otro cartel que anuncia un concierto de solidaridad con Chile en la Salle Pleyel, organizado por el Comité France-Amérique Latine, reunió artistas franceses (Colette Magny, Claude Vinci, etc) y latinoamericanos (Cuarteto Cedrón de Argentina, Huáscar Amaru de Perú, Daniel Viglietti). ${ }^{22}$

18 “Comité Ermont-Eaubonne/Taverny. Peuple chilien”, вPMIP, AFF081.

${ }^{19}$ Cartel "Guatemala. Le génocide d'un peuple en lutte". BPмIP, AFF015.

20 "Non à l'intervention yankee en Amérique centrale". BPMIP, AFF180.

${ }^{21}$ Cartel "Guatemala, 25 ans de dictature, 25 ans de repression. Amnesty International". вPмIP, AFF035; Cartel "Guatemala, 25 ans de dictature, 25 ans de repression. Amnesty International”. BPMIP, AFF035.

${ }^{22}$ El Comité France-Amérique Latine se fundó en noviembre de 1970. Era próximo al Parti Communiste francés y al militantismo cristiano, en colaboración con el Comité de Soutien au Peuple du Paraguay y a la Association Française des Juristes Démocrates. 
Cuadro 1. Colectivos emisores de los carteles de solidaridad Francia-América Latina del fondo de la Biblioteca Pierre Monbeig del IHEAL y número de carteles identificados a su cuenta

1. Comité de Soutien à la Lutte Révolutionnaire du Peuple Chilien

2. Movimiento de la Izquierda Revolucionaria (MIR)

3. Parti Socialiste Chilien

4. Femmes de l'Unité Populaire/Unión Popular Femenina 2

5. Comité Chili 1

6. Comité Coordinateur de la Gauche Chilienne à Paris 1

7. Comité de Défense des Prisonniers Politiques du Chili 1

8. Association des Familles des Disparus (Chile) 1

9. Théâtre de la Résistance (Chile) 3

10. Parti Socialiste (français) 1

11. Mouvement de la Jeunesse Socialiste 1

12. Convention Nationale des Travailleurs (Uruguay) 1

13. Comité de Défense des Prisonniers Politiques en Uruguay 1

14. Comité de Familles des Prisonniers Politiques Uruguayens 1

15. Association Solidarité Franco-Argentine (Grenoble) 1

16. Collectif pour le Boycott de l'Organisation par l'Argentine de la Coupe du Monde de Football

17. Comité de Soutien au Peuple du Paraguay 1

18. Comité Colombie pour la Défense des Droits de l'Homme et des Prisonniers Politiques

19. Comité Amérique Central 1

20. Comité Nicaragua Information 1

21. Association Franco-Nicaraguayenne 1

22. Direction Révolutionnaire Unifiée (El Salvador) 1

23. Comité de Solidarité Avec la Lutte du Peuple d'El Salvador 1

24. Droits de l'Homme-El Salvador 1

25. Front Démocratique Révolutionnaire 1

26. Institut Cinématographique de El Salvador Révolutionnaire 1

27. Comité Guatémaltèque d'Unité Patriotique 1

28. Collectif Guatemala 1 
29. Comité de Solidarité Avec les Luttes du Peuple Mexicain 1

30. Comité France-Amérique Latine 3

40. Coordination des Comités Latino-Américains 1

41. Centre d'Information Sur la Lutte Anti-impérialiste 1

42. Maison pour Tous (Créteil) 1

43. Maison de la Jeunesse et de la Culture (Créteil) 1

44. Musée d'Art et d'Essai (Solidarité des Artistes Latino-Américains

Résidant en France) 1

45. Amnesty International 3

46. Comité Catholique contre la Faim et pour le Dévelopement 1

Fuente: elaboración propia.

Los carteles nunca mencionan nombres de los miembros de los comités y de su eventual colaboración. No obstante, encontramos listas de miembros en folletos diversos. ${ }^{23}$ Por ejemplo, en el Bulletin d'Information du Comité de Défense des Prisonniers Politiques en Uruguay (CDPPU) reconocemos a importantes personalidades del mundo intelectual y político francés como: Simone de Beauvoir, Jean-Paul Sartre, Cecilia Joxe, Paul Blanquard y Daniel Guérin. ${ }^{24}$ Sin embargo, Chouitem (2016) señala que entre, 1973 y 1974, el CDPPU contaba con 25 miembros activos franceses y exiliados uruguayos simpatizantes o militantes del MLN-Tupamaros. La lista del boletín no es, por lo tanto, exhaustiva y, probablemente, el comité incluía a personas que apoyaban la causa sin ser miembros, pero cuya notoriedad social es remarcable. Es probable que muchos exiliados no hayan sido registrados en caso de no estar regularizados en Francia. ${ }^{25}$ El ejemplo de Cecilia Joxe -miembro a la vez del comité del CDPPU y del Comité de Soutien à la Lutte Révolutionnaire du Peuple Chilien-sugiere que una persona podía apoyar a más de un comité.

\footnotetext{
${ }^{23}$ Estos folletos están disponibles en la biblioteca La Contemporaine y en la biblioteca Pierre Monbeig.

${ }^{24}$ La lista completa de nombres es: Simone de Beauvoir, Paul Blanquard, Daniel Guérin, Cecilia Joxe, Alain Labrousse, Catherine Lamour, Albert-Paul Lenin, Maud Manoni, François Maspéro, Ernest Mandel, Georges Montaron, Paul Noirot, Georges Pinet, Gisèe Reboul, Michel Rocard, Jean-Paul Sartre, Sophie Vidal Martins, Pierre Vidal Nacquet, Pasteur Wagner.

${ }^{25}$ De hecho, para muchos de ellos la persecución continuó en París, como se aprecia en la novela gráfica de Calle (2017).
} 
En todo caso, la identificación y prosopografía de los integrantes de comités resulta compleja. Por ahora, sólo hemos podido acercarnos a ella de manera somera e informal. ${ }^{26}$

El Comité de Soutien à la Lutte Révolutionnaire du Peuple Chilien (csLRPC) fue uno de los más importantes, en razón de la cantidad y calidad de impresos que produjo, además de sus redes, eventos y visibilidad internacional. ${ }^{27}$ Su objetivo era "preparar a la opinión y comenzar a movilizarla en la perspectiva del enfrentamiento que la derecha fascista estaba preparando" 28 Además, el CSLRPC pugnaba por la liberación de los presos políticos, el fin de la represión, la tortura y desapariciones, y por la ruptura de relaciones entre Francia y la Junta. Sus coordinadores eran: Emmanuel Bridier (economista, presidente), Patrick Boual (ingeniero, secretario general), Alain Joxe (asistente, tesorero). ${ }^{29}$

El CSLRPC buscaba coordinar todas las fuerzas militantes. Desde el golpe de Estado, estableció redes entre grupos franceses y latinoamericanos. Para eso, convocaba reuniones en la casa de la Mutualité, donde participaban, entre otros, el Parti Socialiste, el Comité France Chili, el Parti Comuniste, la Conféderation Générale du Travail (CGT) y la Conféderation Française Démocratique du Travail (CFDT). En especial, el cSLRPC se relacionaba con el Comité France Amérique Latine -dirigido por Dominique Lahalle-, que presionaba a la prensa francesa para denunciar el apoyo a la Junta chilena por el gobierno de Pompidou. ${ }^{30}$

Las redes del CSLRPC y de otros comités de apoyo a Chile también se revelan por carteles que anuncian eventos en otros países europeos, aunque no

${ }^{26}$ Gracias a las conversaciones que pudimos tener con exiliados chilenos, hemos obtenido algunos datos sobre algunos miembros de comités, así como informaciones útiles de interpretación iconográfica. Por cuestiones diversas, preferimos mantener su anonimato. Uno de ellos es antiguo integrante del Comité de Soutien à la Lutte Révolutionnaire du Peuple Chilien de París. Otros dos pertenecieron al France-Amérique Latine de Burdeos.

${ }^{27}$ El CSLRP se creó por un grupo de militantes franceses de diversos partidos políticos. Muchos de ellos habían estado en Chile y fueron testigos de su transición al socialismo. Su origen se remonta a junio de 1973, como un centro de estudios en el marco del CEDETIM (Centre d'Études Anti-impérialistes). Sus miembros publicaron varios impresos, como el boletín especial Chili 1970-1972, la Movilización de Masas (1975).

${ }_{28}$ "Soutien à la lutte révolutionnaire du peuple chilien", en el Grupo documental "Chile", en biblioteca La Contemporaine. Fecha: París, 19 de septiembre de 1973.

29 "Qu'est-ce que c'est que le Comité de soutien au peuple chilien?", en el Grupo documental "Chile", en biblioteca La Contemporaine. FA1315, Fecha: 19 de septiembre de 1973.

${ }^{30}$ Carta de Dominique Lahalle, secretario general del Comité France-Amérique Latine, en Colección Chile, biblioteca La Contemporaine, Fecha: 4 de marzo de 1975. 
los consideramos en nuestro corpus. Uno promueve la Biennale de Venezia de $1974,{ }^{31}$ otro fue editado por el Instituto Nuevo Chile, con sede en Rotterdam, Holanda, dirigido por Jorge Arriate y Jorge Tapia, que llevaban a cabo actividades de promoción de la cultura y el debate político en Chile.

\section{ICONOGRAFÍAS DE LA SOLIDARIDAD}

Un recurso metodológico para un estudio iconográfico de los carteles es cuestionar sus posibles similitudes o "genealogías" respecto a estilos artísticos (de su pasado y presente); las tipografías, los símbolos, los logotipos y otras figuraciones; la presentación temática y narrativas gráficas; así como las técnicas y las propiedades materiales. En cuanto a similitudes, advertimos una clara presencia del repertorio visual de las izquierdas en todas sus variantes, la herencia técnica y conceptual de las artes gráficas de mayo de 1968, y las intersecciones con estilos y modas como el arte pop, la escuela polaca del cartel y las circulaciones iconográficas de la OSPAAAL.

El Parti Socialiste (Ps) francés, que editó varios carteles a favor de la Unidad Popular (UP) chilena, ${ }^{32}$ acogió el símbolo del puño y la rosa, al parecer de origen español, retomado por otros partidos socialistas del mundo. ${ }^{33}$ Cabe mencionar que el Ps francés fue entusiasta con la Up, especialmente después de las elecciones de 1969, porque significaba una alternativa democrática al ejemplo cubano. El Parti Socialiste difundió informaciones sobre la crisis política y económica en Chile a través de la casa de la Mutualité (Giraudier, 2019).

En los carteles abundan iconos de la represión: alambre de púas, barrotes de prisión, cadenas, objetos militares (cascos, botas, fusiles), o manos atadas. ${ }^{34}$ Es frecuente el uso de los colores negro, blanco y rojo. Como es bien sabido, el rojo suele ser metáfora de la violencia, el dolor y la represión. Lo

${ }^{31}$ La Biennale de Venezia de 1974 se dedicó a Chile. Al margen de ser un evento cultural de gran magnitud, era una plataforma de discusión de políticas globales y del futuro de la política italiana. En ella intervinieron artistas comprometidos como el director de teatro Darío Fo, miembro del Partido Comunista Italiano, quien presentó la pieza Guerra di popolo Cile (Falquez, 2015).

${ }_{32}$ Cartel "Soutien au peuple chilien en lutte. Parti Socialiste". BPMIP, AFF076.

33 Según algunos diarios españoles, el logotipo del puño y la rosa fue creado por el diseñador José Cruz Novillo, para el partido socialista de España.

${ }^{34}$ Se pueden mencionar varios ejemplos, como el cartel "Halte à la répression. Exigeons la libération des prisonniers politiques en Amérique Latine”, firmado por el Parti Socialiste Chilien. BPMIP, AFF057. 
encontramos con variantes muy creativas: rostros de personas que lloran sangre, representaciones del mapa del cono sur con aparentes heridas (véase imagen 3), o Pinochet con las manos ensangrentadas. Un cartel elaborado por Siné, reconocido dibujante de Charlie Hebdo, ${ }^{35}$ editado por las Juventudes Socialistas de Francia (Jeunesses Socialistes), caricaturiza al dictador con la boca abierta, escurriendo sangre y mostrando el irónico mensaje "Nous avons libéré le Chili" (Nosotros liberamos a Chile) (véase imagen 4).

Los carteles del MIR chileno son más enfáticos en el binomio rojo-negro, lo que da a sospechar empatía con estéticas anarquistas. De orientación marxista-leninista, el MIR fue uno de los más radicales opositores a la dictadura de Pinochet. Durante su exilio francés, el Movimiento lanzó una agresiva propaganda para reclamar por la desaparición de su líder Bautista van Schouwen, detenido por la DINA en Chile, en diciembre de $1973 .{ }^{36}$ Un cartel lo muestra difuminado - una imagen que en su origen fue fotografía-coloreada en rojo, negro y violeta (véase imagen 5). Esta fórmula sugiere un guiño con el arte pop y las composiciones multicromáticas de Andy Warhol, también presentes en otros carteles políticos, independientemente de su orientación.

Por otra parte, las posibles afinidades del MIR con la revolución cubana se reconocen en su evocación del Che Guevara. Un cartel que impugna la muerte del líder Miguel Enríquez (también emparentada con el arte pop) muestra su silueta difuminada, y detrás de ella, está la imagen popularizada por Alberto Korda. El único texto es una frase atribuida al guerrillero argentino: "Nous savons que dans cette lutte, nous pouvons perdre la vie, mais nous continuerons jusqu'à la victoire" (véase imagen 6). Como se sabe de sobra, la imagen de Korda circuló ampliamente en la imaginería de la izquierda, en buena medida a través de la cartelería de la ospaAAL. Y es posible, también, considerar la influencia de la escuela polaca del cartel en los ilustradores del MIR en Francia, y en especial, de la ilustración "Che si", de Roman Cieslewicz. ${ }^{37}$

35 Siné fue miembro del equipo de dibujantes satíricos de la revista Action aparecida en mayo de 1968. Esta publicación, junto con otras, como Hara-kiri o Siné Massacre, editadas desde principios de la década de 1960, supusieron una transformación radical de las relaciones jerárquicas entre dibujantes y cronistas.

${ }^{36}$ Sin embargo, cuando circularon estas demandas, Van Schouwen ya había sido asesinado. La noticia de su muerte circuló poco tiempo después (Álvarez, Bastías y Castillo, 2018).

${ }^{37}$ La escuela polaca del cartel tuvo una fuerte influencia en Francia entre 1970 y1980 (Famulicki y Kurpic, 2005). A fines de los años sesenta, varios estudiantes franceses se entrenaron en Varsovia con Henryk Tomascewski y crearon colectivos de arte. Uno de ellos fue el Colectivo Grapus (formado en 1970), integrado por Pierre Bernard, Gérard Paris-Clavel y François Miehle 


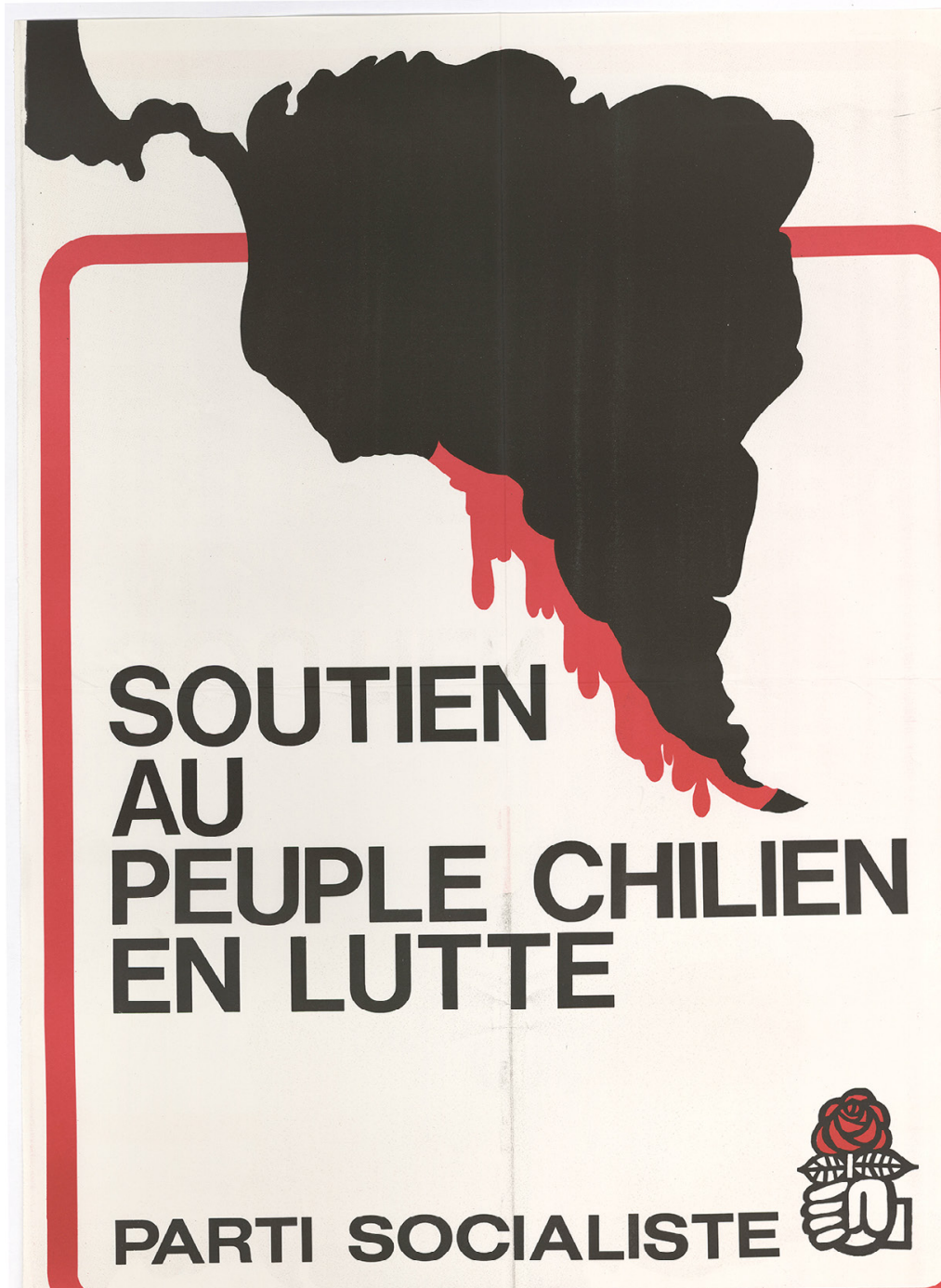

Imagen 3. "Soutien au peuple chilien en lutte. Parti Socialiste". En BPMIP, signatura AFF076. Todos los derechos reservados IHEAL Paris 3, Sorbonne Nouvelle. 


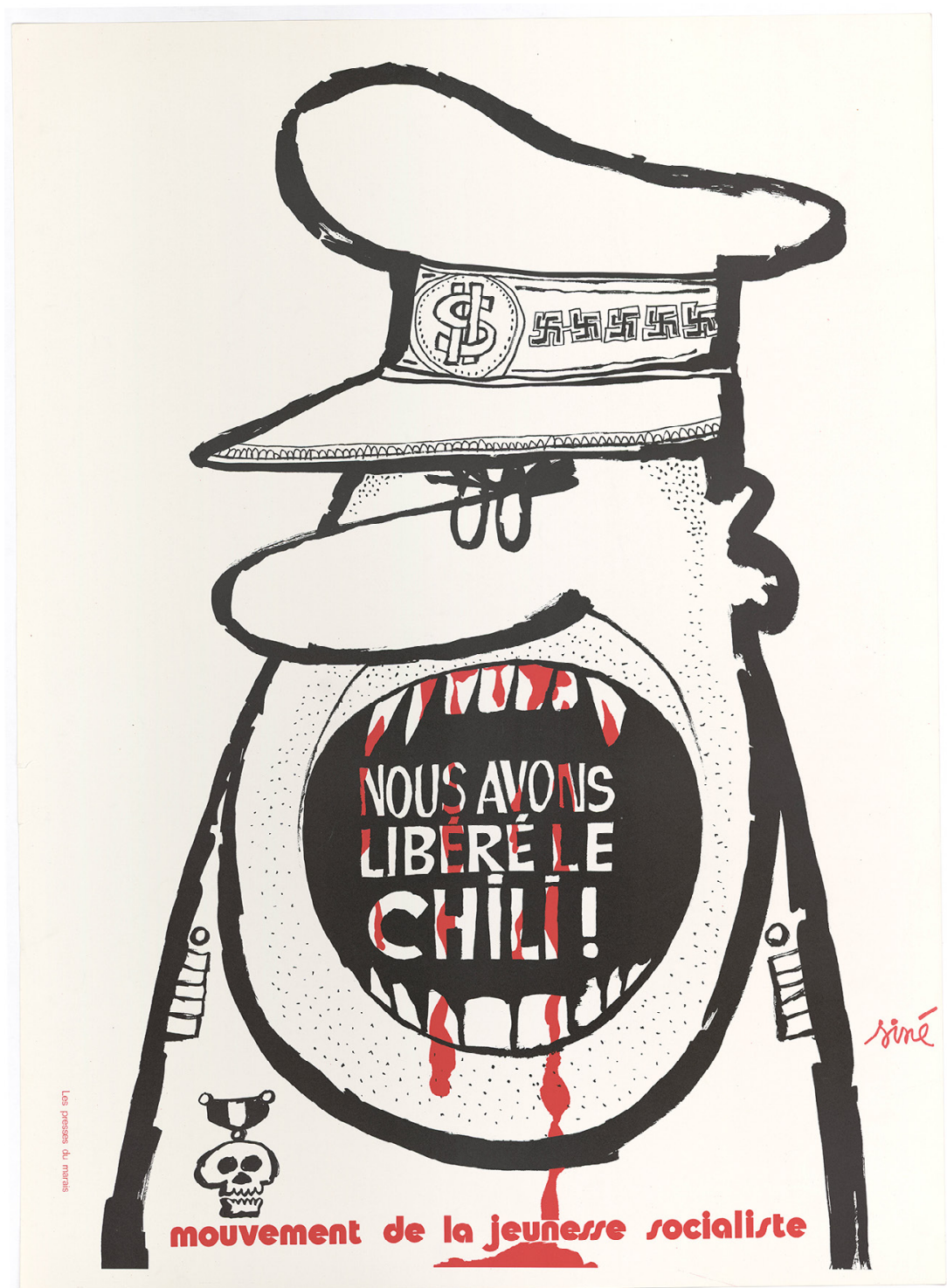

Imagen 4. Mouvement de la Jeunesse Socialiste. "Nous avons libéré le Chili!" En BPMIP, signatura AFF075. Todos los derechos reservados IHEAL Paris 3, Sorbonne Nouvelle. 
26/44 Pilatowsky Goñi, P. y Cabranes, A. / Militancias gráficas: carteles y solidaridad transnacional...

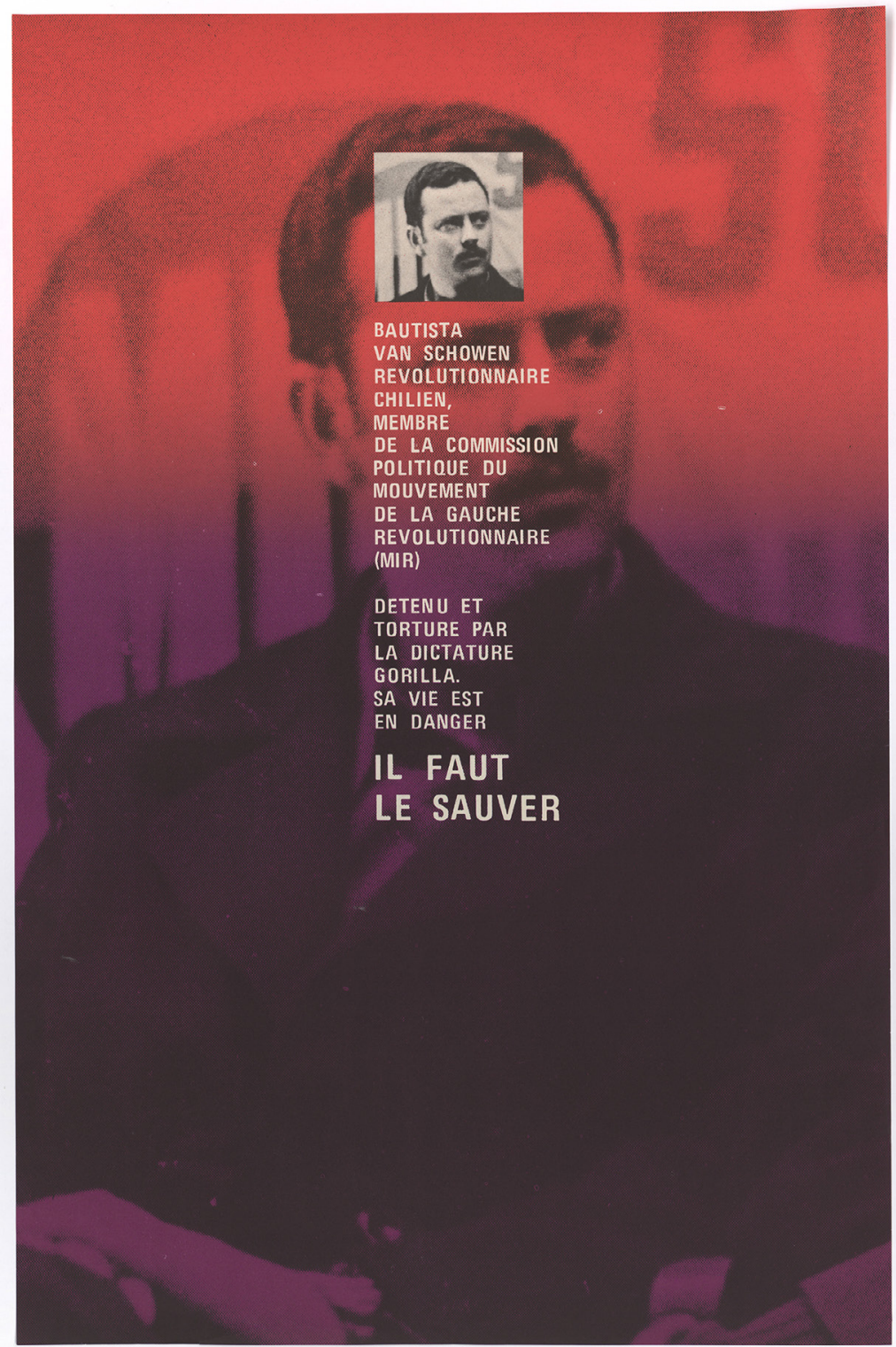

Fig. 5. "Bautista van Schouwen". En BPMIP, signatura AFF080. Todos los derechos reservados IHEAL Paris 3, Sorbonne Nouvelle. 


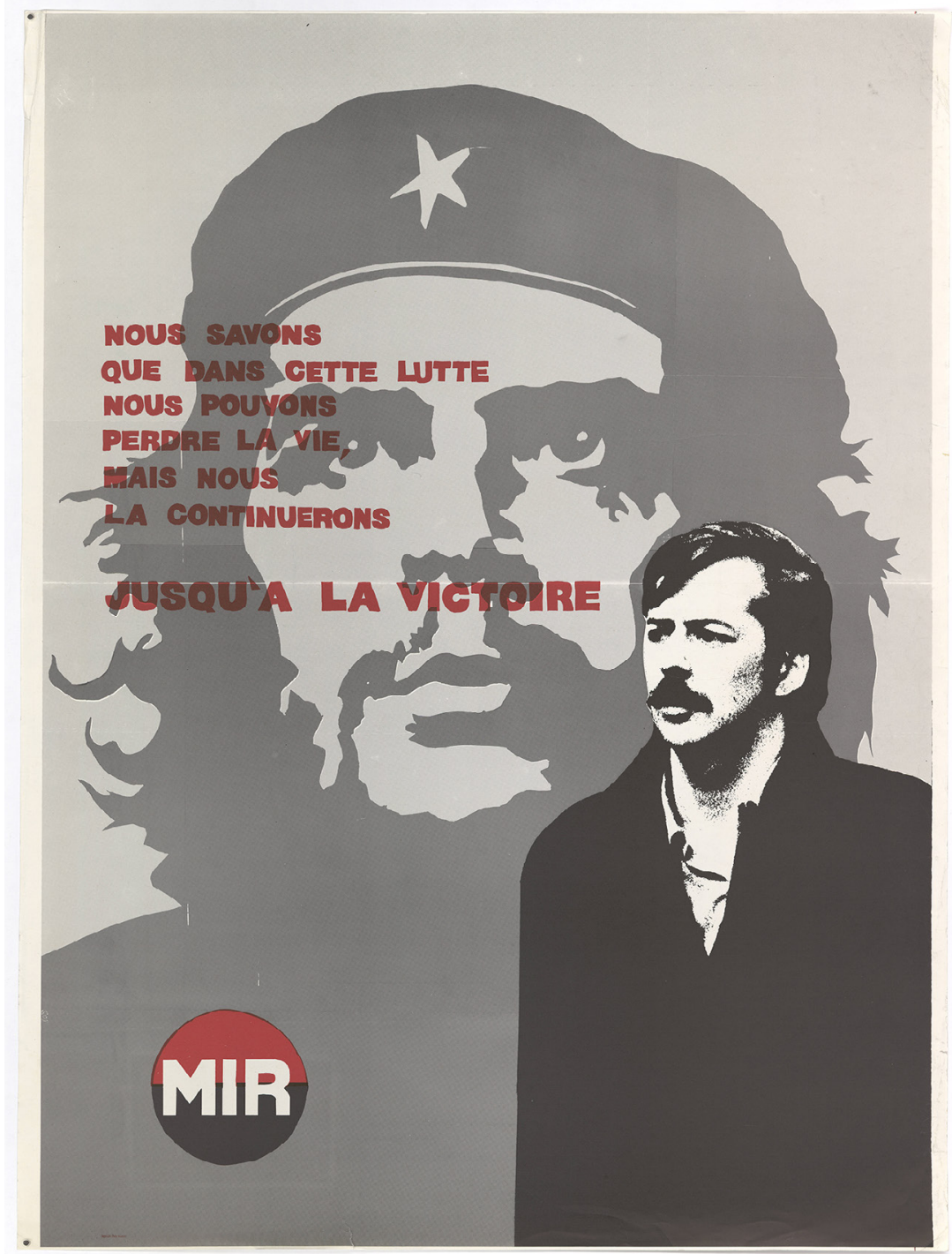

Imagen 6. MIR. "Nous savons que dans cette lutte nous pouvons perdre la vie, mais nous la continuerons. Jusqu’à la victoire”. En BPMIP, signatura AFF001. Todos los derechos reservados IHEAL Paris 3, Sorbonne Nouvelle. 
La imagen del mapa del cono sur fue sinécdoque de pueblos que sufren. El CSLRPC lo adoptó de logotipo y le adjuntó un atributo humano: el mapa es una mano que sujeta un fusil. Parece que el original también se debe a las circulaciones gráficas de la OSPAAAL, como lo muestra el icono diseñado por Asela Pérez Bolado en ocasión de la Jornada Internacional de Solidaridad con América Latina, celebrada en abril de 1973 (Chambarlhac, Hage, y Tillier, 2018, p. 18). Lo cierto es que el logotipo migró por todos los impresos del CSLRPC, incluyendo folletos, revistas, boletines, hojas volantes y pancartas de manifestaciones.

Otros carteles se resisten a la interpretación. Sólo aquellos que los miraron en su momento y compartían su universo de referencias poseen la clave para descifrarlos. En efecto, son crípticos porque tienen su propia historia. Este es el caso de un cartel que aboga por encontrar a los desaparecidos, firmado por Amnistía Internacional y la Association des Familles des Disparus. Es un tríptico con una narrativa: vemos las siluetas de tres personas con los brazos en alto, repetida en tres niveles. En una secuencia de abajo hacia arriba, las figuras generan un efecto cinematográfico de ir desapareciendo progresivamente. Un antiguo miembro del CSLRPC explicó que esta imagen circuló ampliamente entre los militantes y que, en su origen, era una fotografía capturada a distancia, durante un partido en el estadio de fútbol de Santiago. La alusión al estadio, prosiguió, no es menor, pues era uno de los espacios utilizados por la DiNA para encerrar, torturar y asesinar a los presos políticos. ${ }^{38}$

Como última genealogía, cabe reconocer las herencias técnicas y conceptuales del movimiento de mayo de 1968 en Francia. Varios carteles son serigrafías, un procedimiento de impresión muy acudido por ser económico y fácil de utilizar (Gervereau, 1988). ${ }^{39}$ De hecho, la serigrafía fue uno de los medios predilectos de las prácticas contestatarias, de manera que varios autores

(Fraenkel y De Smet, 2016). Roman Cieslewicz, polaco que llegó a París en 1963 trabajó, entre otras, para las revistas Elle y Vogue. Fue él quien elevó a iconos la imagen del Che Guevara y de Mao-Tse Tung, además de la célebre fotografía de Korda en su cartel "Che si". En 2018, el Museo de Artes Decorativas de París rindió tributo al polaco en la muestra Roman Cieslewicz, La fabrique des images, de mayo a septiembre de 2018.

${ }_{38}$ Preferimos mantener el anonimato de esta persona. Por otra parte, esta imagen también podría relacionarse con el "Siluetazo", como se conoce a una acción estético-política difundida en Buenos Aires en 1983 para denunciar las desapariciones de personas. Cartel "Chili: Que sont devenus les prisonniers des disparus?”, firmado por Amnesty International y la Association des Familles des Disparus. BPMIP, AFF055.

${ }^{39}$ Esta técnica surgió en Estados Unidos durante la segunda guerra mundial y se introdujo en Francia a través del taller de Guy Rougemont de la Escuela de Bellas Artes de París. 
llamaron al acto del cartel y del graffiti una forma en que "los muros hablan" (les murs bavards) (Crettiez y Piazza, 2013, p. 8). El espíritu del 68 alimentó, para decirlo con palabras de Chambarlhac (2018), "las potencialidades de la creación colectiva contra la tiranía de la individualidad”, de manera que, por lo común, ninguna personalidad reivindicaba las serigrafías y, si acaso, tan sólo aparecían timbradas por el taller que las produjo. Un cartel que lleva el título "Chili résistance", muestra la imagen abstracta de un casco militar partido en pedazos en un fondo rojo y blanco. ${ }^{40}$ Es una serigrafía producida por el Atelier Front des Artistes Plasticiens de la Ecole des Beaux-Arts de París activa desde el 13 de mayo de 1968 (Chambarlhac, Hage y Tillier, 2018, p. 23). Otro cartel muestra a un obrero que se dispone a aplastar un tanque que lleva como atributos un signo de dólares y una suástica, ${ }^{41}$ una imagen, por cierto, muy recurrente en otras imágenes producidas por el mismo taller.

\section{La denuncia de la política francesa a las dictaduras}

Las izquierdas francesas criticaron duramente las relaciones diplomáticas entre los gobiernos de Georges Pompidou y Valérie Giscard D'Estaing, y los gobiernos dictatoriales en América Latina, especialmente, con Pinochet. Para decirlo con palabras de Gárate (2015), "A Augusto Pinochet se le reconoce universalmente como un ícono de las dictaduras latinoamericanas y del mundo 'en desarrollo' construido gráficamente como una de las más reconocibles encarnaciones del mal del último tercio del siglo xx" (p. 15).

En 1974 llegó el nuevo embajador de la Junta chilena a Francia, Fernando Durán Villarreal. En las primeras imágenes progolpe, afirma Gárate (2015), "la figura de Pinochet aún está ausente, pues la dictadura se manifiesta primeramente como una junta militar, que todavía no se individualiza, pero que ejerce la violencia represiva sin contemplación" (p. 20). A manera de fotografía de prontuario, varios comités solidarios publicaron el rostro de Durán, exigiendo que saliera del país. El CSLRPC popularizó la caricatura, idéntica o con variaciones, de un personaje ficticio de dos caras, al estilo de Jano bifronte, en que una sonríe en gesto diplomático, mientras la otra, vuelta hacia el lado inverso, es de un militar malencarado empuñando un fusil (véase ima-

${ }^{40}$ Cartel "Chili. Résistance". BPMIP, AFF064.

${ }^{41}$ Cartel "Chili. Solidarité. Résistance". BPMIP, AFF063. 
gen 7). En otro cartel, Jano está personificado: su mitad opresora es Pinochet y su mitad diplomática Durán, quien da la mano a Pompidou. ${ }^{42}$ La escena simula una suerte de pacto o alianza, quizá celebrado con hipocresía. Otro cartel que reclama contra un mitin fascista simula una alegoría de la duplicidad con dos ratas entrelazando sus colas, aludiendo respectivamente a los fascistas chilenos y a los fascistas franceses. ${ }^{43}$

Entre octubre y principios de noviembre Pinochet comienza a aparecer personificando la dictadura chilena (Gárate, 2015, p. 21). Los cartelistas lo representan acudiendo libremente al humor, la metáfora y la sátira. Cabe recordar que en Francia, a diferencia de los países latinoamericanos, los grupos contestatarios no sufrían una censura similar, de manera que los ilustradores pintaron libremente al dictador sin reparo en mostrarlo con atributos de brutalidad y ambición, como las manos ensangrentadas, la esvástica nazi y un signo de dólares.

\section{El antiimperialismo y la lucha por los derechos humanos}

Desde finales de la década de 1970 y con énfasis a principios de los años ochenta, los gobiernos represivos de varios países centroamericanos orquestaron genocidios, desapariciones y torturas contra grupos rebeldes y la población civil. Varios contaron con el apoyo de Estados Unidos, alimentando una fuerte reacción antiimperialista y anticapitalista ${ }^{44}$ que se extendió, por supuesto, a Francia.

Tres carteles de diferentes tamaños, que reprochan el imperialismo estadunidense, incluyen la bandera de este país junto con las breves palabras "no" y "contra". La imagen del "guerrillero anónimo" es un componente habitual de la gramática visual antiimperialista, que intersecta los colores de aquella bandera con el negro y rojo de la protesta. Un cartel del Comité de Solidarité avec la Lutte du Peuple de El Salvador presenta la figura de un hombre que se funde con un mapa de Centroamérica, esgrimiendo un fusil

${ }^{42}$ Cartel "L'ambassadeur de la Junte chilienne en France. Le gouvernement français s'apprête à l'accueillir”, firmado por el CSLRPC. BPMIP, AFF074. AFF079.

${ }^{43}$ Cartel "Contre le meeting fasciste du 19 décembre", firmado por el CSLRPC. BPMIP,

${ }^{44}$ Por ejemplo, la "contra" nicaragüense fue apoyada por el gobierno de Reagan, minando el régimen revolucionario sandinista inaugurado en 1979. 

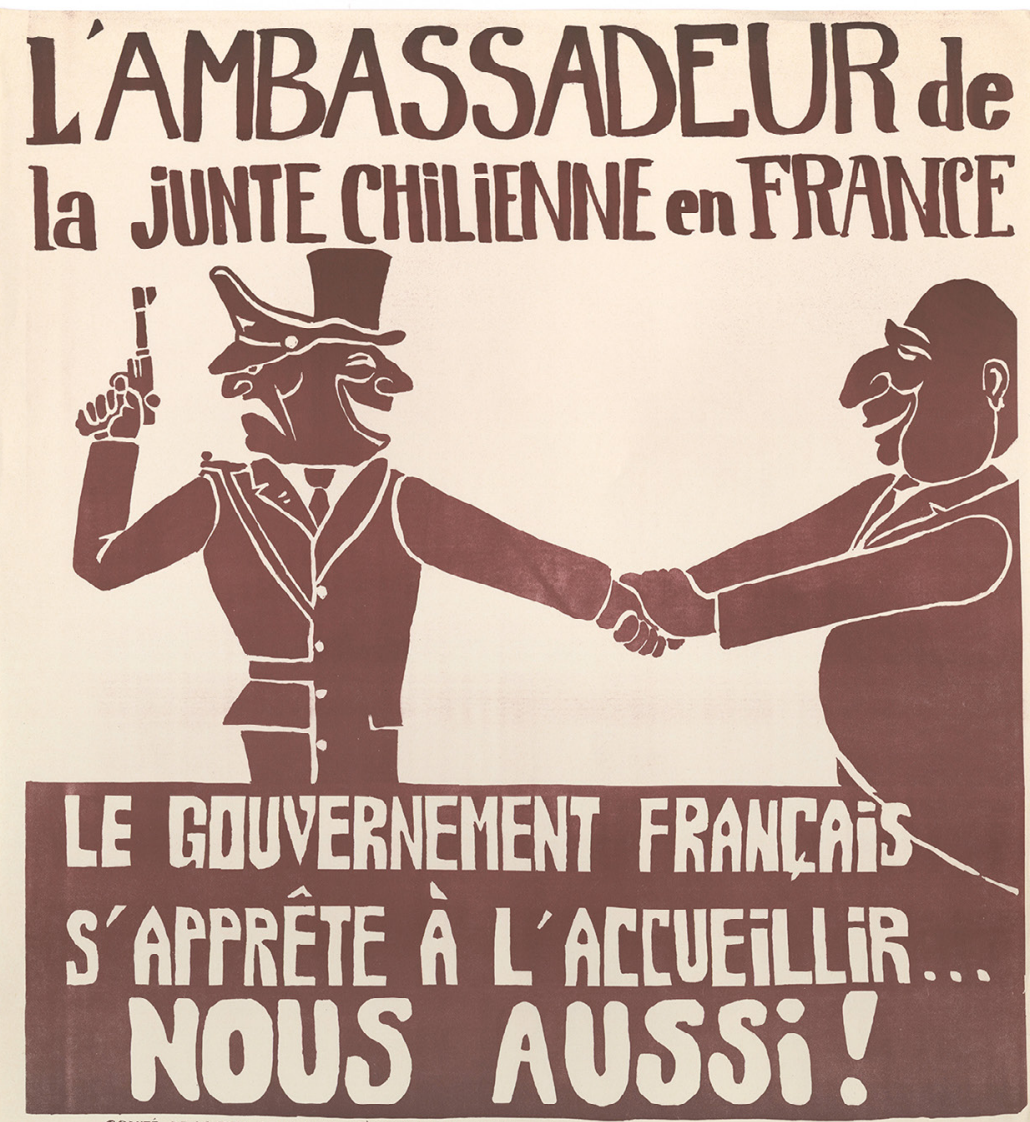

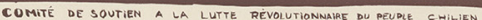

Imagen 7. Comité de Soutien à la Lutte Révolutionnaire du Peuple Chilien. "L'ambassadeur de la Junte chilienne en France”. En BPMIP, signatura AFF074. Todos los derechos reservados IHEAL Paris 3, Sorbonne Nouvelle. 
AK-47. ${ }^{45}$ Las imágenes de ancianos, con gestos de sufrimiento, parecen funcionar como recurso emotivo. Un cartel difundido por el Comité Guatemala acompaña la frase "Répression et tout passera" (véase imagen 8), con la imagen de una mujer de edad, con ropa típica y la mirada baja. ${ }^{46}$

Por su parte, las organizaciones no gubernamentales, en lucha a favor de los derechos humanos, fijaron sus propias iconografías: el color blanco, partes del cuerpo (manos y pies), flores y plantas, y la paloma blanca. ${ }^{47} \mathrm{Am}$ nistía Internacional y Secours Populaire eran las más visibles en el paisaje internacional, ${ }^{48}$ pero la constelación de entidades solidarias en Francia era densa y reunía sociedades de diversos credos. Podemos citar al Comité Inter-mouvements Auprés des Évacués (CIMADE), France Terre d'Asile (FTDA), la Action des Chrétiens pour l'Abolition de la Torture (АСАT) y el Comité Catholique pour la Faim et le Développement (CCFD). La CIMADE, de origen protestante, fue una de las organizaciones de mayor protagonismo ayudando a refugiados de todas las formas posibles, incluyendo hospedaje, ayuda material, psicológica y administrativa (Volovitch-Tavares, 2013). Junto con France Terre d'Asile, y otras organizaciones, la cIMADE presionó al gobierno de Pompidou para que acogiera refugiados venidos de Chile. Al parecer tuvieron éxito, pues muchos chilenos obtuvieron el estado de refugiados a partir de la Oficina Francesa de Protección de Refugiados (OFPRA). ${ }^{49}$

Por demás, el cimade tenía amplias conexiones con América Latina, lo cual se debía, por una parte, a que ocupaba una posición dentro del Comité Oecumenique des Églises (que reunía a los responsables católicos y pro-

${ }_{45}^{45}$ Cartel "No. Non à l'intervention américaine au Salvador". BPMIP, AFF044.

${ }^{46}$ Cartel "Solidarité Guatemala. Répression et tout passera". BPMIP, AFF011. La presentación de ancianos, niños, familias, en contextos de pobreza, se caracteriza con la gráfica pacifista. Sin embargo, los medios de comunicación explotaron estas imágenes, como denunciaron los cineastas colombianos Carlos Mayolo y Luis en la noción "pornomiseria" en su mediometraje "Agarrando pueblo".

${ }^{47}$ El símbolo de la paloma blanca se atribuye a Pablo Picasso, quien la presentó por primera vez en el Primer Congreso Mundial por la Paz en 1949. La paloma migró de ese Congreso a la gráfica de Amnistía Internacional y de otras organizaciones pacifistas.

${ }_{48}$ Amnistía Internacional desplegó una intensa campaña visual en la que solicitó el concurso de renombrados ilustradores como: Joop Lieverst, Joan Miró, Alain Carrier, Olivur Vio Neyst, Seymour Chwast y Lemel Yossi. Véase el catálogo de la exhibición Change this world: 50 years of posters for Amnesty international 1961-2011. en https://www.amnesty.org/en/documents/ АСТ30/067/2011/en/

${ }^{49}$ Volovitch-Tavares (2013) afirma que entre 1975 a 1993 se aceptaron 9142 solicitudes de asilo de las 9495 solicitadas. 


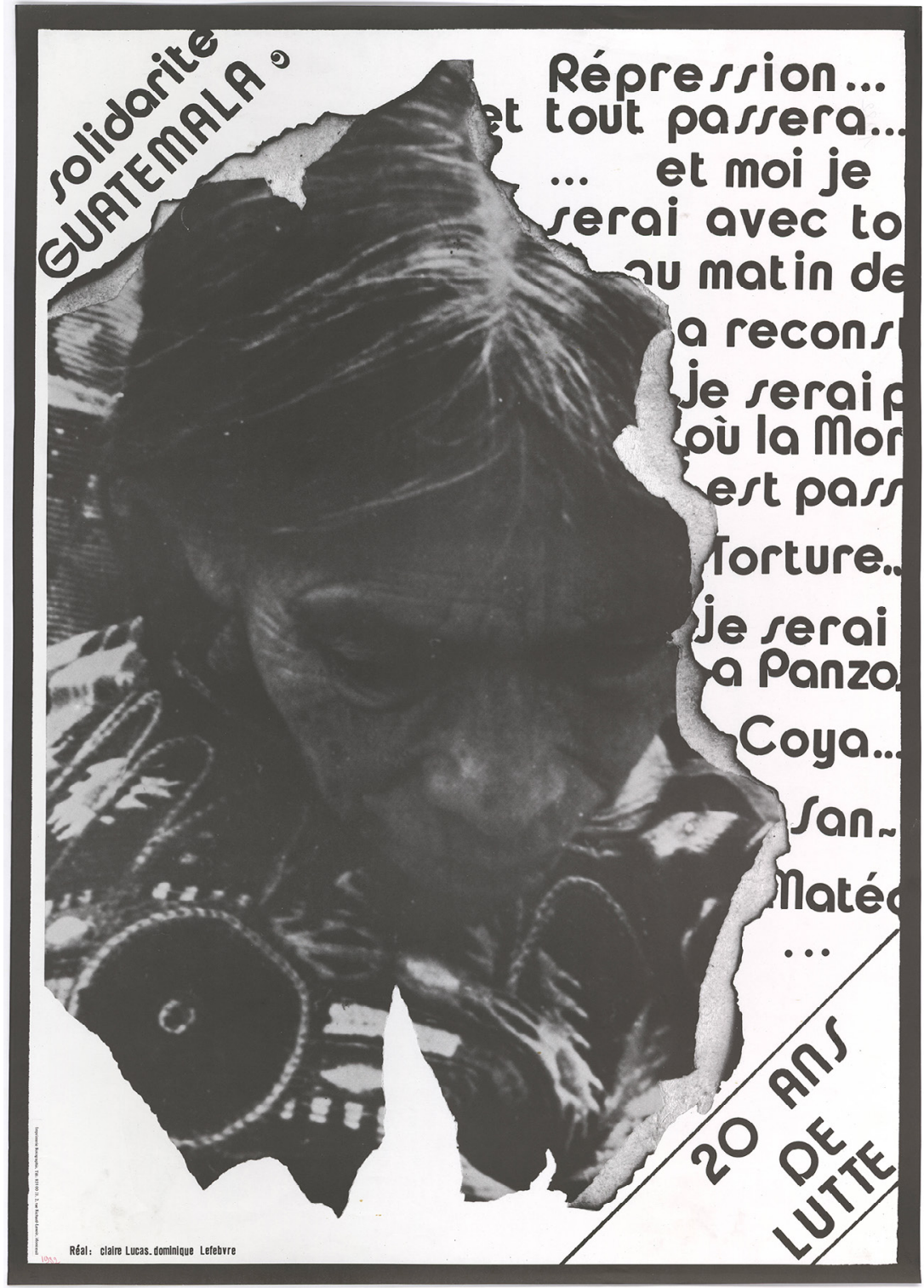

Imagen 8. "Solidarité Guatemala. Répression et tout passera". En BPMIP, signatura AFF011. Todos los derechos reservados IHEAL Paris 3, Sorbonne Nouvelle. 
testantes en el "Comité Pro Paz" de Chile) y por otra, a las misiones de su delegado Julio Amaral a Argentina, Bolivia y Perú (Volovitch-Tavares, 2013, p. 9). Varios carteles atestiguan la acción del CIMADE a favor de los artistas latinoamericanos. Uno promueve un concierto de la folclorista boliviana Luzmila Carpio titulado "Cantos y música de los indígenas quechuas de Potosí Bolivia" (enero de 1984), que se llevaría a cabo en la iglesia de Saint Merry. ${ }^{50}$

Cabe mencionar que Saint Merry acogió numerosos eventos a favor de la paz en América Latina. El Comité de Défense des Prisonniers Politiques de l'Uruguay, organizó el recital "La canción de los prisioneros", interpretado por el músico Daniel Viglietti y el escritor Eduardo Galeano, en apoyo a las víctimas de la dictadura de 1973-1985, de ese país del cono sur. Rey Tristán (2007) cita un comentario de Viglietti sobre el evento: "Él [Galeano] anticipaba textos de libros próximos y yo cantaba canciones mías y con eso hacíamos uniones. Pero en París dimos un recital que se llamó La chanson des prissionniers porque lo hicimos todo sobre la base de materiales que nos habían llegado de adentro. Quien sabe cuántos autores que nunca figuraron con nombre propio, porque había poemas hermosos ahí" (p. 269).

El cartel que promueve el recital evoca El hombre de Vitruvio de Leonardo Da Vinci. Se trata de un esbozo en papel amarillo, de un hombre desnudo en cuclillas, con los brazos hacia atrás -quizá atados-, y su rostro invisible, cubierto por el cabello. A diferencia del hombre de Da Vinci, enmarcado en figuras geométricas que definen la proporción del cuerpo, el hombre del cartel solidario está rodeado por varios círculos concéntricos cuyo centro apunta al corazón. La imagen puede interpretarse como una mira telescópica que apunta y dispara. En efecto, de la espalda del hombre parece surgir el impacto de una bala (véase imagen 9).

Las fotografías de niños en escenas de su vida cotidiana fueron otro ingrediente predilecto en la retórica visual del pacifismo. Es el caso de los carteles del Comité Católico contra el Hambre y por el Desarrollo (CCFD),

${ }^{50}$ Luzmila Carpio es un personaje de gran interés en la historia de las solidaridades y por su papel en la promoción de la música andina en Europa. De hecho, es considerada la cantante indígena más famosa, comprometida con la identidad y cultura indígenas. Fue condecorada con la Orden Nacional del Mérito en Francia y en 2006 fue nombrada embajadora de Bolivia en este país por el gobierno de Evo Morales. Véase el sitio web de Luzmila Carpio en https://www. luzmilacarpio.tv/, Cartel "Luzmila Carpio. Chants et musique des indiens quechuas de Potosí Bolivie”. BPMIP, AFF005. 


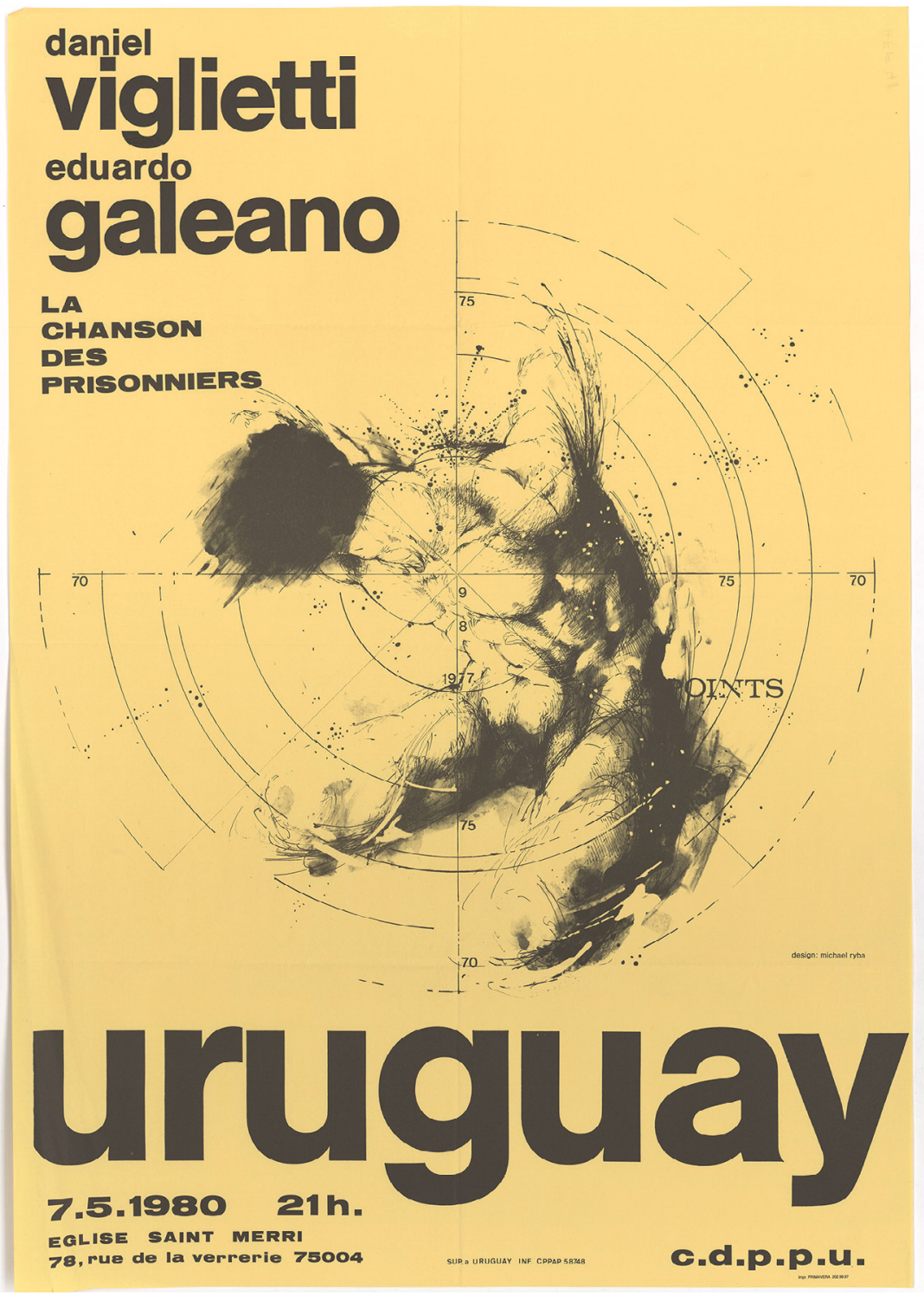

Imagen 9. Uruguay. "La chanson des prisonniers". En BPMIP, signatura AFF048. Todos los derechos reservados IHEAL Paris 3, Sorbonne Nouvelle. 
a menudo ilustrados con imágenes de gran calidad. ${ }^{51}$ Uno que promueve su proyecto "Arc-en-ciel. Construir el Perú" (1983), sugiere una metáfora en que los niños (aún en condiciones de pobreza parecen símbolos del futuro y la esperanza), juegan sobre la obra negra de un edificio (una construcción en su plena materialidad, evidentemente)..$^{52}$

Además de la gráfica de las organizaciones no gubernamentales, las imágenes de niños circularon por otros registros de la militancia, como en las exposiciones de grandes museos. Podemos referir a "Guatemala au cœur", organizada en colaboración entre el Comité Guatemalthèque d'Unité Patriotique (CGUP) y el Museo del Hombre. En ella se involucraron el director del Comité, Manuel José Arce, y académicos asociados al laboratorio de Etnología del Museo, como el antropólogo Jean Guiart -su director-, y la investigadora del Centre National de la Recherche Scientifique (cNrs), Anne Marie Hocquenghem. ${ }^{53}$ Parece que la exposición fue ambiciosa, a decir por el amplio espectro temático que cubría: historia, música, literatura, arqueología y estadísticas recientes sobre Guatemala. Su misión era buscar el reconocimiento de las culturas mayas, que según se escribía en el reporte eran "generalmente discriminadas o folclorizadas". ${ }^{54}$

Es posible que la exposición incluyera fotografías, pues en el cartel que la promueve vemos la imagen de dos niños sentados sobre unos escalones (quizá parte de un resto arqueológico), que miran hacia un mismo lado con aparente ignorancia de la cámara. Podría suponerse que la imagen refiere gráficamente a una leyenda en el reporte de la exposición, la cual afirma que el pueblo guatemalteco "tiene dos rostros (la cultura indígena y la cultura ladina), que comienzan a mirar en la misma dirección".

${ }^{51}$ El CCFD se fundó en 1960 como respuesta a los llamados a la acción contra el hambre exigidos por la FAo y el Papa Juan XXIII. Continúa sus actividades hasta nuestros días. Véase su sitio web en https://ccfd-terresolidaire.org/

${ }_{52}$ Cartel "CCFD, Construire au Pérou. Arc-en-ciel 1983". BPMIP, AFF009.

${ }_{53}$ Esta arqueóloga del área andina estuvo implicada en proyectos con el CIMADE, como el libro Guatemala, des enfants déssinent (1982), en colaboración con Catherine Vigor.

${ }^{54}$ Reporte de la exposición Guatemala au coeur, obtenido en línea del sitio web de Anne Marie Hocquenghem, en http://www.hocquenghem-anne-marie.com/20101204/a_faire_ page_expositions/1982_guatemala_au_coeu.paris.pdf 


\section{PARÍS: CAPITAL CULTURAL LATINOAMERICANA}

El arte y las culturas de América Latina florecieron en París favorecidas, en buena medida, por la llegada de exiliados y la acción solidaria. Como señala Prognon (2008) sobre el exilio chileno, las actividades culturales fueron cruciales en las prácticas militantes, especialmente desde fines de la década de 1970, una vez que se desvanece la espera por la normalización de la situación política en Chile (p. 210). Así, mientras la oferta cultural de París aumentaba, lo hacía el interés por lo latinoamericano.

Los carteles revelan que la vida cultural solidaria se expresó en espacios de lo más variopinto: desde las salas de conciertos más glamurosas hasta los apartados teatros, cines y centros sociales "subterráneos". Algunos artistas latinoamericanos llegaron a convertirse en "embajadores" informales de sus países, como los grupos folcloristas de la llamada nueva canción chilena, afiliada políticamente con la Unidad Popular. Uno de los más conocidos es Quilapayún (Chile), y muchos otros grupos formados en Francia, o que continuaron su trayectoria en este país: Trabunche, Karaxú, Karumanta, Calenche, Héctor Pavez, el Coro Unidad (Prognon, 2008, p. 209), y el grupo de danza Víctor Jara. Los carteles que anuncian conciertos de grupos y artistas como estos siguen las modas gráficas de su tiempo, como uno de autoría de Trauco Murúa (1980) dedicado a un concierto de Quilapayún, inscrito en modas psicodélicas. ${ }^{55}$ Esta creatividad gráfica contrasta con la sobriedad y realismo de otros carteles, como el arriba mencionado que lleva la fotografía de la folclorista boliviana Luzmila Carpio. ${ }^{56}$

Los carteles revelan, además, que muchos eventos culturales de la solidaridad, destinados, entre otras cosas, a colectar fondos para las víctimas, encontrar refugios, y difundir informaciones, eran acciones conjuntas. Un cartel anuncia una velada organizada por el Comité por los Prisioneros Políticos de Uruguay, que tendría lugar en la Casa de Brasil, de la Ciudad Universitaria..$^{57} \mathrm{~A}$ la par de recaudar fondos, el evento movilizaba la una red entre Brasil, Francia y Uruguay, extendiendo al esparcimiento juvenil, colectivo y transnacional, lo que era en origen una demanda política.

\footnotetext{
${ }_{55}$ Cartel "Quilapayún. Por Trauco Murúa, 1980". BPMIP, AFF023.

${ }^{56}$ Cartel "Luzmila Carpio. Chants et musique des indiens quechuas de Potosí Bolivie". вPMIP, AFF005.

${ }^{57}$ Cartel "Solidarité avec les prisonniers politiques de l'Uruguay. Carnaval. Maison du Brésil”. BPMIP, AFF038.
} 
Por otra parte, los artistas latinoamericanos formaron sus propias redes. Tal es el caso de José Balmes, pintor chileno exiliado en París, ${ }^{58}$ quien realizó los carteles para la compañía de el Théâtre de la Résistance-Chili, que el dramaturgo también chileno Gustavo Gac-Artigas fundó en la capital francesa durante su exilio. ${ }^{59}$

Por su parte, las artes visuales difundieron las condiciones de violencia en América Latina en sus propios códigos, como el llamado "realismo tercermundista" ${ }^{60}$ El Instituto Cinematográfico de El Salvador revolucionario ${ }^{61}$ anunció en Francia el documental El Salvador. El pueblo vencerá (1980), del director puertorriqueño Diego de la Texera. Este documental fue ampliamente premiado en eventos afines al comunismo como el Festival de Cine de La Habana (1980) y el premio de oro del Festival de Cine de Moscú (1981). El cartel que anuncia la presentación del documental está compuesto por varios retratos fotográficos en blanco y negro, con figuras de cuerpo entero de aparentes guerrilleros (quizá participantes en el documental). ${ }^{62}$

Por último, posiblemente debido a la omnipresencia cultural latinoamericana, junto a la emergencia de los derechos humanos, varias instituciones académicas y culturales francesas organizaron mesas redondas, conferencias, jornadas de estudios, cursos y exposiciones de interés histórico, literario y antropológico. Entre otras: el Ministerio de Cultura, el Institut des Hautes Études de l'Amérique Latine (IHEAL), Sciences Po, la Maison des Cultures du Monde, el museo Grand Palais, el parque de la Villette, la Maison de l'Amérique Latine, la Alliance Française, y el centro Georges Pompidou.

${ }^{58}$ José Balmes, pintor chileno-catalán, fue un doble exiliado. Llegó a Chile en 1930 a causa de la guerra civil española, y en 1973 salió nuevamente al exilio debido a sus relaciones con Unidad Popular. Véase el largometraje "Balmes, el doble exilio de la pintura" (2001), de Pablo Trujillo Novoa. Balmes ganó el premio de dibujo de la Bienal Americana de Artes Gráficas de 1971 organizada en el Museo de La Tertulia de Cali (Colombia). https://archive.org/details/ PrimeraBienalAmericanaDeArtesGraficas/page/n1/mode/2up, abierto el 22 de julio de 2020.

${ }^{59}$ Cartel "Théatre de la résistance-Chili". BPMIP, AFF052.

${ }^{60} \mathrm{El}$ "realismo tercermundista" surgió en el marco de movimientos revolucionarios en los proyectos del Instituto Cubano de Arte e Industria Cinematográficos, creado por Fidel Castro. Fue una alternativa a las producciones de Hollywood, consideradas un medio imperialista para las izquierdas (Clark, 1997, pp. 142-143).

${ }^{61}$ Este Instituto se fundó en 1980 por las Fuerzas Populares de Liberación con el objetivo de revelar la injusticia social, la impunidad militar, la represión a la oposición (Luers, 1993). ${ }^{62} \mathrm{C}$ artel "El Salvador. El pueblo vencerá. Institut Cinématographique de El Salvador Révolutionnaire”. BPMIP, AFF021. 
Este revival americanista aprovechó conmemoraciones y aniversarios que reforzaban la idea de una historia común entre América Latina y Europa. Por ejemplo, un cartel anuncia el festejo del 200 Aniversario de Bolívar "El Libertador", en la Maison des Cultures du Monde. Estaba animado por un concierto del venezolano Alfonso Montes y su coterránea, la bailarina Sonia Sanoja. ${ }^{63}$ Por otra parte, el 500 aniversario de la conquista de América y el bicentenario de la revolución francesa sirvieron para crear una conexión simbólica entre el patriotismo francés y la lucha por la libertad de los pueblos latinoamericanos del siglo xx. La iconografía de este revival reactivó antiguas alegorías (como la "América", personificada en una mujer con un penacho de plumas), y el gorro frigio identificado con la Marianne de la revolución francesa. Un cartel promueve una serie de conferencias en la ciudad de Huilles dedicadas a la "Historia de los Derechos del Hombre". En el cartel vemos un cuadro con la imagen de una medalla en la que un hombre de color lleva un gorro frigio, mientras que otro cuadro se ilustra con una fotografía del documento de la Declaración de los Derechos del Hombre. ${ }^{64}$ Si bien es cierto que las instituciones culturales francesas mostraron compromiso y generosidad en el estudio y promoción de lo latinoamericano, sus acciones también delataban un cierto espíritu colonialista y fascinación por lo exótico. Salvo muchas excepciones, varios eventos acuden a la palabra "indien", que denota lo indígena como una unidad cultural homogénea en la que no se reconocen diferencias ni étnicas ni nacionales.

\section{CONCLUSIÓN: HACIA UNA HISTORIA VISUAL DE LA SOLIDARIDAD}

Susan Sontag (1970) escribió que: "los carteles son agresivos porque aparecen en el contexto de otros carteles [...]. Los carteles presuponen el concepto de espacio público como un teatro de la persuasión" (p. 196). En consonancia, nuestro estudio corrobora que los carteles son síntoma de una nueva forma de hacer política y de dinamizar las redes de solidaridad. Los carteles convi-

${ }^{63}$ Cartel "200ème anniversaire de Bolívar El Libertador. Ministère de la Culture, Maison des cultures du monde, Alliance Française”. BPMIP, AFF010.

${ }^{64}$ Cartel "Exposition organisée par la Ville de Houilles à l'occasion du 140e anniversaire de l'abolition de l'esclavage et du 40e anniversaire de la Déclaration des Droits de l'Homme". BPMIP, AFF154. 
vieron con otros carteles (políticos, publicitarios, turísticos, etc.), que a su vez se integran en un sistema de comunicación más amplio (que incluye folletos, boletines, libros y pancartas). Si bien nuestras fuentes iluminan que París era uno de los nodos solidarios de mayor densidad, el "teatro de la persuasión" establecido por el mundo del cartel, fijaba lenguajes, símbolos, códigos extendidos a nivel transnacional.

La colección de carteles de la BPMIP ofrece claves: nombres de comités, instituciones, artistas, y personas implicadas. Nos permite cartografiar la ubicación de sedes de comités y otros sitios de reunión, lo que constituye una vía para reconocer, por ejemplo, a las entidades más visibles y con mayores recursos, su espacialidad y sus relaciones entre sí y con el medio francés. Sin embargo, identificar con precisión a los actores y la complejidad de dichas relaciones, sigue siendo un reto para estudiar el fenómeno solidario en Francia.

Por otra parte, esta investigación cuestionó la existencia de una "cultura visual". Con métodos iconográficos, identificamos la recurrencia de símbolos de la represión y la violencia, así como las gramáticas visuales establecidas por el uso de colores, símbolos y palabras. El cartel de protesta solidaria, como aquí se ha visto, fue producto de una amplia circulación en las artes gráficas que nos remite, entre otras, a la influencia de la revolución cubana, a la escuela polaca del cartel, y a las serigrafías de mayo del 68 .

En suma, pretendemos invitar a nuevos investigadores a considerar la riqueza del cartel como fuente histórica. Es evidente, sin embargo, que su naturaleza de material efímero impone retos que no acechan a otras fuentes. Las colecciones son escasas (bibliotecas, archivos y colecciones privadas y museos) y los carteles son aún objetos poco frecuentados que todavía no cuentan con criterios de clasificación unificados. Sin embargo, las nuevas exigencias historiográficas - con énfasis especial en la historiografía de la guerra fría-, así como los nuevos enfoques transdisciplinarios, ponen de manifiesto que el cartel es sin duda un fenómeno indisociable a las prácticas políticas del siglo xx.

\section{LISTA DE REFERENCIAS}

Agreda, J. M. y Helm, C. (2016). Solidaridad con la revolución sandinista. Comparativa de redes transnacionales: los casos de la República Federal de Alemania y España. Naveg@mérica. Revista Electrónica Editada por la Asociación Española de 
Americanistas, 17. Recuperado de https://revistas.um.es/navegamerica/article/ view/271921

Álvarez, M., Bastías, J. y Castillo, C. (2018). Bautista Van Schouwen: que la dignidad se haga costumbre. Santiago: Pehuén.

Artivismo. El papel de la cartelería y la música en la lucha contra el Apartheid Sudafricano en los años 70' y 80' (2016). Las Palmas de Gran Canaria: Casa África.

Blecha, L. (2016). Vietnam in Latin America! The Nicaraguan revolution in the Austrian Press. Naveg@mérica. Revista Electrónica Editada por la Asociación Española de Americanistas, 17. Recuperado de https://revistas.um.es/navegamerica/article/ view/271891

Calle, A de la (2017). Pinturas de guerra. Madrid: Reino de Cordelia.

Camacho Padilla, F. y Ramírez Palacio, L. (2016). Las imágenes de las guerrillas centroamericanas en las redes de la solidaridad internacional de Suecia. Naveg@ mérica. Revista Electrónica Editada por la Asociación Española de Americanistas, 17. Recuperado de https://revistas.um.es/navegamerica/article/view/271901

Chambarlhac, V., Hage, J., Tillier, B. (2018). Le trait 68. Insubordination graphique et contestations politiques, 1966-1977. París: Citadelles \& Mazenod.

Chouitem, D. (2016). Redes francesas de apoyo a los presos políticos y detenidos-desaparecidos uruguayos. Nuevo Mundo Mundos Nuevos. Dor: https://doi. org/10.4000/nuevomundo.69619

Christiaens, K., Goddeeris, I. y Rodríguez García, M. (eds.) (2014). European Solidarity with Chile, 1970s-1980s. Frankfurt am Main: Peter Lang Editions.

Clark, T. (1997). Arte y propaganda en el siglo Xx. Madrid: Akal.

Compagnon, O. (2013). Chili, 11 septembre 1973: Un tournant du xxe siècle latino-américain, un événement-monde. Revue Internationale et Stratégique, 91(3), 97105. DoI: https://doi.org/10.3917/ris.091.0097

Contamin, J. y Le Noé, O. (2010). La coupe est pleine Videla! Le Mundial 1978 entre politisation et dépolitisation. Le Mouvement Social, 230(1), 27-46. DoI: https://doi. org/10.3917/lms.230.0027

Crettiez, X. y Piazza, P. (2013). Iconographies rebelles. Cultures et Conflits, 91-92, 7-11. Recuperado de http://journals.openedition.org/conflits/18768

De Giuseppe, M. y Ágreda, J. M. (2016). Redes internacionales de apoyo y solidaridad con grupos, actores y movimientos político-sociales latinoamericanos, 1955-1995. Nuevo Mundo Mundos Nuevos. Recuperado de http://journals.openedition.org/ nuevomundo/69607

Falquez, R. (2015). Libertà al Cile: Alternative Media and Art as Information at the 1974 Venice Biennale. Art journal, 74(2), 44-61. 
Famulicki, J. C. y Kurpik, M. (2005). L'affiche polonaise de 1945 à 2004: des slogans et des signes. París-Varsovia: Ed. La Découverte BDIC.

Fraenkel, B., Gouiran, M., Jakobowicz, N. y Tesnière, V. (2013). Affiche-action: quand la politique s'écrit dans la rue. Exposición del 14 de noviembre de 2012 al 24 de febrero de 2013. París: BDIC, Hôtel National des Invalides.

Fraenkel, B. y De Smet, C. (2016). Études sur le collectif Grapus: entretiens et archives 1970-1990. París: B4.

Franco, M. (2004). Testimoniar e informar: exiliados argentinos en París (19761983). Amérique Latine Histoire et Mémoire. Les Cahiers ALHIM, 8. DoI: https://doi. org/10.4000/alhim.414

Franco, M. y Tahir, N. (2007). Les argentins et la France des années 1970. Droits de l'homme et solidarité. Hommes et Migrations, 1270, 20-31. Dor: https://doi. org/10.3406/homig.2007.4658

Gárate, M. (2015). El nacimiento de un monstruo. El golpe de Estado en Chile y la imagen de Augusto Pinochet a través de las caricaturas de la prensa escrita francesa (1973-1990). Caravelle, 104, 87-114. DoI: https://doi.org/10.4000/caravelle.1588

Garland, A. (2018). From the 'Tricontinental' to the Global South: race, radicalism, and transnational solidarity. Durham: Duke University Press.

Gastaut, A. (dir.). (2019). Affiches cubaines. Révolution et cinéma, 1959-2019. París: Musée des Arts Décoratifs.

Gervereau, L. (1988). La sérigraphie à l'école des Beaux-Arts. Entretien avec Rougemont. Matériaux pour l'Histoire de Notre Temps, 11-13, 180-183.

Giraudier, E. (2019). Le parti socialiste français dans la recomposition du parti socialiste chilien à partir de 1973. Fondation Jean Jaurès. Recuperado de https://jean-jaures.org/ nos-productions/le-parti-socialiste-francais-dans-la-recomposition-du-parti-socia liste-chilien-a

Hage, J. (2016). De la guerre du Vietnam à l'abolition de l'apartheid. Mobilisations internationales et circulations graphiques (pp. 47-51). En Internationales graphiques: collections d'affiches politiques 1970-1990. París/Lyon: BDIC.

Hocquenghem, A. M. y Vigor, C. (1982). Guatemala, des enfants déssinent. París: cimADE (Collection Espoirs).

Judt, T. (2005). Postwar. A History of Europe since 1945. Nueva York: Penguin Press.

Kalter, C. (2016). The Discovery of the Third World. Decolonisation and the rise of the New Left in France, 1950-1976. Cambridge: Cambridge University Press.

Lebeau, E. (15 al 20 de julio, 2018). El Museo Internacional de la Resistencia Salvador Allende (1975-1990). Transnacionalización del Museo de la Solidaridad en el exilio. Ponencia presentada en el Congreso Internacional de Americanistas, Salamanca. 
Léger, R. (2013). Cuba gráfica: histoire de l'affiche cubaine. Montreuil: L'Échappée.

López, A. L., Lebrero, H., Higueras, E., Reig, P. (2020). Carteles en transición. Cuenca: Ediciones de la Universidad de Castilla La Mancha.

Luers, R. (1993). El Salvador: La guerra transparente. Chasqui. Revista Latinoamericana de Comunicación, 46, 38-40. DoI: https://doi.org/10.16921/chasqui.v0i46.654

Martín, A. y Rey, E. (2017). Revolutionary violence and the new left. Transnational perspectives. Nueva York: Routledge.

Mirzoeff, N. (1999). An introduction to visual culture. Londres y Nueva York: Routledge.

Mitchell, W. J. T. (1994). Picture theory: Essays on verbal and visual representation. Chicago y Londres: The University of Chicago Press.

Moine, C. (2015). Sources et archives audiovisuelles de la solidarité internationale: le cas chilien (archivo audiovisual). En Bibliothèque La Contemporaine, París, Nanterre.

Morales Campos, R. (2008). El cartel cubano de la Tricontinental. Rebelión. Recuperado de https://rebelion.org/el-cartel-cubano-de-la-tricontinental/

Picker, K. (2017). Activismo transnacional y solidaridad, de Cuba a Centroamérica. Revista de la Red de Intercátedras de Historia de América Latina Contemporánea, 4(7), 120-140.

Plante, I. (2013). Argentinos en París. Arte y viajes culturales durante los años sesenta. Buenos Aires: Edhasa.

Prognon, N. (2008). La culture chilienne en exil en France: une forme de résistance à la Junte (1973-1994). Pandora. Revue d'Études Hispaniques, 205-220. Recuperado de https://hal.archives-ouvertes.fr/hal-01143720

Rey, E. (2007). Memorias de la violencia en Uruguay y Argentina: golpes, dictaduras, exilios, 1973-2006. Santiago de Compostela: Universidad de Santiago de Compostela.

Stites, J. (2014). Human rights and transnational solidarity in cold war Latin America. Madison: University of Wisconsin Press.

Sontag, S. (1970). Posters: advertisement, art, artifact, commodity. En D. Stermer, The art of revolution. 96 posters from Cuba. Londres: Pall Mall Press.

Tardy, C. y Tesnière, V. (dirs.). (2016). Internationales graphiques: collections d'affiches politiques 1970-1990. Exposición. París: Bibliothèque de Documentation Internationale Contemporaine (BDIC)/Musée d'Histoire Contemporaine/Hôtel National des Invalides, 17 de febrero al 29 de mayo.

Texera, D. de la (dir.) (1980). El Salvador: El pueblo vencerá (documental). El Salvador: Instituto Cinematográfico de El Salvador Revolucionario FMLN.

Tortti, M. C. (2014) La nueva izquierda argentina (1955-1976). Socialismo, peronismo y revolución. Rosario: Prohistoria Ediciones. 
Trujillo Novoa, P. (dir.). (2011). Balmes, el doble exilio de la pintura (Largometraje). Chile: TripioFilms Producciones Independientes.

Van Ommen, E. (2016). The sandinista revolution in the Netherlands: The Dutch Solidarity committes and Nicaragua (1977-1990). Naveg@mérica. Revista Electrónica Editada por la Asociación Española de Americanistas, 17. Recuperado de https:// revistas.um.es/navegamerica/article/view/271861

Volovitch-Tavares, M. C. (2013). La Cimade et l'accueil des "réfugiés en provenance du Chili”, du coup d'État militaire (11 septembre 1973) au début des années 1980. En La Cimade et l'accueil des réfugiés. Identités, répertoire d'action et politique de l'asile, 1939-1994. Nanterre: Presses Universitaires de Paris Nanterre. DoI: https://doi. org/10.4000/books.pupo. 2567

Weiss, H. (2017). International communism and transnational solidarity. Boston: Brill (Colección Studies in Global History).

\section{OTRAS FUENTES}

\section{Bibliotecas}

BPMIP Bibliothèque Pierre Monbeig (вРм), Institut des Hautes Études de l'Amérique Latine (IHEAL), Paris 3 Sorbonne Nouvelle.

BDIC Bibliothèque de Documentation Internationale Contemporaine (La Contemporaine), Universidad de París X Nanterre.

BNF Bibliothèque Nationale de France. 